\title{
Assessment of the role of MAP kinase in mediating activity-dependent transcriptional activation of the immediate early gene Arc/Arg3.1 in the dentate gyrus in vivo
}

\author{
Jennifer K. Chotiner, ${ }^{1,2,3}$ Jessica Nielson, ${ }^{1,2,3}$ Shannon Farris, ${ }^{1,2,3}$ Gail Lewandowski, ${ }^{1,2,3}$ \\ Fen Huang, ${ }^{1,2,3}$ Karla Banos, ${ }^{4}$ Ray de Leon, ${ }^{5}$ and Oswald Steward ${ }^{1,2,3,5,6}$ \\ ${ }^{1}$ Department of Anatomy and Neurobiology, Reeve-Irvine Research Center, University of California at Irvine, Irvine, California \\ 92697, USA; ${ }^{2}$ Department of Neurobiology and Behavior, Reeve-Irvine Research Center, University of California at Irvine, Irvine, \\ California 92697, USA; ${ }^{3}$ Department of Neurosurgery, Reeve-Irvine Research Center, University of California at Irvine, Irvine, \\ California 92697, USA; ${ }^{4}$ Department of Kinesiology and Nutritional Science, California State University, Los Angeles, Los \\ Angeles, California 90032-8162, USA; ${ }^{5}$ Center for the Neurobiology of Learning and Memory, University of California at Irvine, \\ Irvine, California 92697, USA
}

\begin{abstract}
Different physiological and behavioral events activate transcription of Arc/Arg3.1 in neurons in vivo, but the signal transduction pathways that mediate induction in particular situations remain to be defined. Here, we explore the relationships between induction of $\mathrm{ArC} / \mathrm{Arg} 3.1$ transcription in dentate granule cells in vivo and activation of mitogenactivated protein (MAP) kinase as measured by extracellular-regulated kinase $1 / 2$ (ERK1/2) phosphorylation. We show that ERK1/2 phosphorylation is strongly induced in dentate granule cells within minutes after induction of perforant path long-term potentiation (LTP). Phospho-ERK staining appears in nuclei within minutes after stimulation commences, and ERK phosphorylation returns to control levels within $60 \mathrm{~min}$. Electroconvulsive seizures, which strongly induce prolonged $\mathrm{Arc} / \mathrm{Arg} 3.1$ transcription in dentate granule cells, induced ERK1/2 phosphorylation in granule cells that returned to control levels within $30 \mathrm{~min}$. Following 30, 60, and $120 \mathrm{~min}$ of exploration in a novel complex environment, Arc/Arg3.1 transcription was activated in many more granule cells than stained positively for p-ERK at all time points. Although Arc/Arg3.1 transcription was induced in most pyramidal neurons in CAl following exploration, very few pyramidal neurons exhibited nuclear p-ERK1/ 2 staining. Local delivery of U0126 during the induction of perforant path LTP blocked transcriptional activation of Arc/Arg3.1 in a small region near the injection site and blocked Arc/Arg3.1 protein expression over a wider region. Our results indicate that activation of Arc/Arg3.1 transcription in dentate granule cells in vivo is mediated in part by MAP kinase activation, but other signaling pathways also contribute, especially in the case of $\operatorname{Arc} / \operatorname{Arg} 3.1$ induction in response to experience.
\end{abstract}

Activity-dependent changes in synaptic efficacy are thought to underlie information storage in the nervous system, and there is general agreement that modifications that persist for more than a few hours require alterations in gene expression (Kandel 2001). For the synaptic modifications involving enhanced synaptic efficacy (like long-term potentiation [LTP]), steps in the induction of gene expression are thought to include: (1) synaptic activation that is sufficient to induce $\mathrm{Ca}^{2}$ influx through $N$-methyl-D-aspartate (NMDA) receptors and/or L-type voltage-sensitive calcium channels (VSCCs); (2) signaling from activated synapses to the nucleus; (3) induction of transcription of immediate early genes (IEGs) including transcription factors and effector genes; and (4) delivery of critical gene products (either mRNA or protein) to activated synapses that are somehow marked for modification (Malenka and Bear 2004). For the part of the process that involves delivery of mRNA to synapses, there may also be local control over the translation of mRNAs in dendrites (Schuman et al. 2006). How

\footnotetext{
${ }^{6}$ Corresponding author.
}

E-mail osteward@uci.edu; fax (949) 824-2625.

Article is online at http://www.learnmem.org/cgi/doi/10.1101//m.1585910. these different processes operate in different settings remains to be worked out.

Studies of the unique IEG Arc (Lyford et al. 1995), also known as Arg3.1 (Link et al. 1995), have illuminated molecular mechanisms that exist in neurons that allow selective delivery of newly synthesized mRNA and protein to synapses (Steward et al. 2001). Arc/Arg3.1 transcription is strongly induced by synaptic activation and behavior (Lyford et al. 1995; Guzowski et al. 1999; Vazdarjanova et al. 2002), and newly synthesized Arc/Arg3.1 mRNA is transported into dendrites where it localizes selectively at active synapses (Steward et al. 1998). This provides a mechanism whereby Arc/Arg3.1 protein can be locally synthesized.

Experiments involving activation of the perforant path in vivo have revealed that both induction of transcription and targeting of Arc/Arg3.1 mRNA to active synapses require signals generated by NMDA receptors (Steward and Worley 2001), but the molecular cascades that mediate the two processes remain to be defined. One candidate mechanism for inducing transcription is the mitogen-activated protein (MAP) kinase pathway. At least one form of stimulation that induces perforant path LTP strongly induces phosphorylation of extracellular regulated kinase $1 / 2$ (ERK1/2) in dentate granule cells. Phosphorylated ERK1/2 (p-ERK) 
appears in the nucleus either as a result of translocation from the cytoplasm or phosphorylation of nuclear ERK (Davis et al. 2000). This study also demonstrated that pharmacological blockade of MEK with SL327 blocked perforant path LTP and activation of transcription of the IEG zif 268; however, the role of MAP kinase in activating $\operatorname{Arc} / \operatorname{Arg} 3.1$ transcription was not explored. Waltereit et al. (2001) showed that Arc was strongly induced by highfrequency stimulation (HFS) of the perforant path, that this occurred at lower stimulus intensities than were required to induce c-fos, and that in neurons in culture, Arc induction required the activity of protein kinase A and MAP kinase. Other evidence links ERK activation in granule cells and transcriptional activation of Arc/Arg3.1 following infusion of brain-derived neurotrophic factor (BDNF) into the dentate gyrus, which induces a slowly developing form of perforant path LTP (Ying et al. 2002).

Although these studies are consistent with the idea that the MAP kinase cascade could mediate synapse to nucleus signaling, it is not clear whether MAP kinase is the necessary and sufficient signaling pathway responsible for transcriptional activation of Arc/Arg3.1 in vivo. For example, one recent study describes a transcriptional switch mechanism in the Arc/Arg3.1 promoter with binding sites for cAMP response element binding (CREB), serum response factor (SRF), and myocyte enhancer factor 2 (MEF2) (Kawashima et al. 2009). Mutation of any one of these abrogated transcriptional activation of a reporter driven by the Arc promoter in primary neurons in culture. Similarly, Pintchovski et al. (2009) report that Arc transcription is regulated by SRF and another novel transcription factor. These results suggest the possible involvement of multiple kinase pathways in triggering Arc induction, but which of these pathways actually operate to induce Arc in different settings in vivo remains to be established.

Here, we explore the degree to which MAP kinase activation is critical for activating Arc/Arg3.1 transcription in response to induction of perforant path LTP in vivo and other events that induce Arc/Arg3.1 transcription in dentate granule cells. Our results are consistent with the interpretation that the MAP kinase pathway is capable of inducing Arc/Arg3.1 in granule cells, but indicate that other signal transduction pathways also play a role in response to physiological events in vivo.

\section{Results}

\section{High-frequency synaptic activation triggers rapid ERK phosphorylation throughout the dendrites and cell bodies of dentate granule cells}

Consistent with previous studies, HFS of the perforant path strongly activates ERK phosphorylation in dentate granule cells. For example, Figure 1 illustrates the dramatic increases in immunostaining for p-ERK throughout the dendritic and cell body laminae of the dentate gyrus that are seen 4 min after completion of three rounds of $10400-\mathrm{Hz}$ trains, each of which was followed by 10 test pulses (a total of 30 high-frequency trains and 30 test pulses delivered over a period of $10 \mathrm{~min}$ ). In this case, the rat was perfused $\sim 2$ min after the end of the third test period, which was $\sim 4 \mathrm{~min}$ after the last high-frequency train. On the control side (contralateral to the stimulation), the highest level of staining is in stratum radiatum and stratum oriens (the sites of termination of the commissural/associational system), with a sharp boundary at the border with stratum lacunosum-moleculare (the site of termination of projections from the entorhinal cortex). In the dentate gyrus (Fig. 1C), the granule cell layer is lightly stained, and there is a trilaminar staining pattern in the molecular layer, with moderate levels of staining in the inner molecular layer (the site of termination of the commissural/associational system), low levels of staining in the middle molecular layer (the site of termination of the medial perforant path), and moderate levels of staining in the outer molecular layer (the site of termination of the lateral perforant path). Individual neurons with even higher levels of labeling can be seen, but fewer neurons exhibit high levels in animals that are perfused without an antecedent period of anesthesia (Steward et al. 2007).

Control experiments confirm that the striking induction of ERK phosphorylation is due to the HFS. For example, $10 \mathrm{~min}$ of test stimulation followed by 15 min of paired pulse stimulation caused no change in ERK phosphorylation (Fig. 1, cf. E, control side, and F, stimulated side). This pattern of paired pulse stimulation did not lead to any detectable change in perforant path response amplitude, however. This is important, because in the hippocampus proper, paired pulse stimulation of CA3-CA1 synapses induces long-term depression (LTD), and also leads to decreases in ERK phosphorylation as measured by Western blot

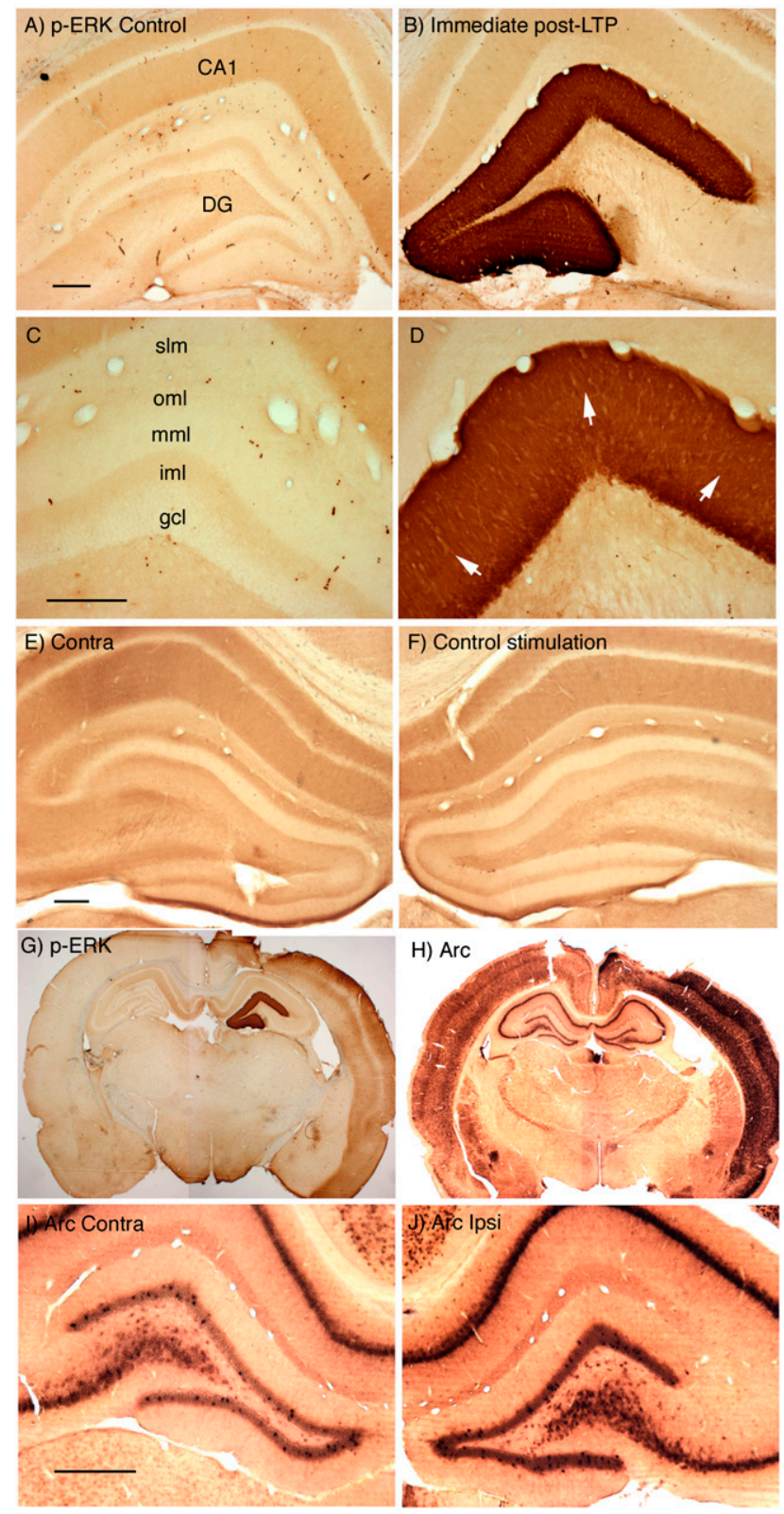

Figure 1. (Legend on next page) 
(Gallagher et al. 2004). All the sections for this and subsequent figures were taken very near the micropipette track.

It should be noted that animals that were prepared for neurophysiological experiments and perfused within $30 \mathrm{~min}$ exhibited increases in immunostaining for p-ERK throughout the neocortex on the side on which stimulating and recording electrodes had been placed regardless of the stimulation that was delivered. An example is shown in Figure $1 G$, which is the case illustrated in Figure 1, A-D, in which the animal was perfused about $30 \mathrm{~min}$ after placing the electrodes. There was also strong induction of IEG expression throughout the neocortex as revealed by in situ hybridization for Arc/Arg3.1 mRNA (Fig. 1H). At this time, there was minimal induction of $A r c / A r g 3.1$ mRNA expression in dentate granule cells in response to the HFS (Fig. 1I,J). It is likely that the induction of ERK phosphorylation and IEG expression in the neocortex are triggered by the manipulations involved in preparing animals for neurophysiology (the craniotomy and placement of electrodes). Nevertheless, we have not carried out experiments to identify the signals underlying cortical activation of p-ERK and IEGs. Interestingly, there was no induction of IEG expression in the CA1 region of the hippocampus except in a few neurons immediately surrounding the micropipette track, suggesting that it may be direct injury to the cortex rather than electrode penetration that is responsible for ArC/Arg3.1 induction.

Previous studies have shown that Arc/Arg3.1 transcription is detectable within $5 \mathrm{~min}$ after $40-\mathrm{Hz}$ stimulation of the perforant path (Steward et al. 2007). If MAP kinase activation is alone responsible for inducing Arc/Arg3.1 transcription, then ERK activation and synapse to nucleus signaling must occur prior to induction of Arc/Arg3.1 transcription.

To define the time course of MAP kinase activation following induction of perforant path LTP, animals received either one round (10 trains) or three rounds (30 trains) of $400-\mathrm{Hz}$ stimulation, and ERK phosphorylation was assessed at various times thereafter (Fig. 2). Delivery of one round of 10 trains every $10 \mathrm{sec}$ required $1 \mathrm{~min}$ and $40 \mathrm{sec}$, and the animal was perfused $\sim 3 \mathrm{~min}$ after the end of the HFS stimulation period, which was $\sim 5 \mathrm{~min}$ after the first HFS train. All other cases received three rounds of $400-\mathrm{Hz}$ stimulation with interspersed test stimulation as described above.

Figure 1. High-frequency synaptic activation triggers ERK phosphorylation ( $p$-ERK) throughout the dendrites and cell bodies of dentate granule cells. $(A-D)$ Pattern of immunostaining for $p$-ERK in rats in which the perforant path has been activated at high frequency to induce LTP. $(A, C)$ Pattern of staining on the control side contralateral to the stimulation. (CA1) Ca1 region of the hippocampus; (DG) dentate gyrus; (gcl) granule cell layer; (iml) inner molecular layer; $(\mathrm{mml})$ middle molecular layer; (oml) outer molecular layer; (slm) stratum lacunosum-moleculare of the hippocampus. $(B, D)$ Pattern of staining on the side that received three rounds of $10400-\mathrm{Hz}$ trains, each of which was followed by 10 test pulses (a total of 30 trains and 30 test pulses). Trains and test stimulation were delivered at $1 / 10 \mathrm{sec}$ intervals, so that the entire induction protocol required $10 \mathrm{~min}$. Animals were perfused $\sim 2 \mathrm{~min}$ after the end of the third test period, which was $\sim 4$ min after the last high-frequency train. Note striking activation of ERK phosphorylation throughout the dendritic and cell body laminae of the dentate gyrus. White arrows in $D$ indicate the band of staining in the activated lamina. $(E, F)$ Pattern of immunostaining for $p$-ERK is not altered by stimulation that does not induce LTP. Here, the rat received test stimulation and then $15 \mathrm{~min}$ of paired-pulse stimulation. Note that immunostaining for $\mathrm{p}$-ERK was comparable on stimulated $(E)$ and control $(F)$ sides. $(G)$ Induction of ERK phosphorylation throughout the neocortex on the side on which stimulating and recording electrodes had been placed. This is the same animal shown in $A-D$. $(H)$ The strong induction of $\operatorname{Arc} / \operatorname{Arg} 3.1$ expression throughout the neocortex as revealed by in situ hybridization for $\operatorname{Arc} / \operatorname{Arg} 3.1$ mRNA. $(I, J)$ Minimal induction of Arc/Arg3.1 mRNA expression in dentate granule cells $12 \mathrm{~min}$ after the start of the HFS. Scale bars, $250 \mu \mathrm{m}$.
Even one round of HFS triggered striking activation of ERK throughout the dendritic and cell body layers of the dentate gyrus (Fig. 2, 5-min time point), although the increases were not as great as seen following three rounds (cf. Fig. 1). Ten minutes after delivering three rounds of HFS with interspersed test stimulation, p-ERK staining was more intense throughout the dendritic and cell body layers. Robust increases in p-ERK immunostaining were still evident 15 min after the cessation of HFS, although staining was somewhat less intense than at earlier time points. Thirty minutes after three rounds of HFS, staining in the dendritic and cell body lamina was further diminished, and by $60 \mathrm{~min}$ after three rounds of HFS, staining was similar to that seen in the contralateral hippocampus that received no stimulation.

\section{Nuclear localization of $\mathrm{p}$-ERK occurs within minutes after initiation of stimulation}

ERK could mediate synapse to nucleus signaling via translocation of p-ERK from the cytoplasm to the nucleus or phosphorylation of nuclear ERK where it could activate SRF-mediated gene expression. Consistent with this, studies of facilitation in Aplysia and LTP in hippocampal slices have revealed phosphorylation of nuclear ERK following stimulation paradigms that induce late-phase, protein synthesis-dependent synaptic modifications, but not after stimulation paradigms that induce only transient potentiation (Martin et al. 1997; Patterson et al. 2001). Accordingly, it was of interest to assess the appearance of p-ERK in granule cell nuclei at various times after HFS of the perforant path.

When animals were killed $5 \mathrm{~min}$ after the start of a single bout of 10 trains (which is not sufficient to induce persistent LTP), nuclei exhibited low levels of staining in comparison with the surrounding cytoplasm (Fig. 3B). Nuclear staining was prominent, however, 10 min after three bouts of HFS (30 trains, Fig. 3C). The absence of p-ERK in nuclei after 10 trains could be due to the fact that less overall stimulation was delivered (10 trains vs. 30 trains), or to insufficient time for nuclear translocation or phosphorylation of nuclear ERK. To distinguish between these possibilities, 30 high-frequency trains were delivered at a rate of $1 / 10 \mathrm{sec}$ over a period of 5 min without intervening test stimulation, and the animal was perfused $\sim 2$ min after the end of the stimulation period (so, 7 min after the start of the HFS). Thirty trains induced robust p-ERK staining throughout the dendritic lamina and in the cell body layer, and many nuclei exhibited high levels of immunostaining (Fig. 3D). Because 10 trains is not sufficient to cause nuclear localization of p-ERK, the threshold could not have been reached until more than 10 trains had been delivered (which at a rate of one train per 10 sec could be no sooner than 1 min and $40 \mathrm{sec}$ after the start of the 30 train series). Thus, the time required for the appearance of phospho-ERK in the nucleus after the threshold has been reached can be no more than about $5 \mathrm{~min}$ and $20 \mathrm{sec}$, and could be considerably less.

\section{Electroconvulsive seizures induce transient MAP kinase activation and prolonged $\mathrm{ArC} / \mathrm{Arg} 3.1$ transcription}

One disadvantage for studies of the time course of MAP kinase activation and Arc/Arg3.1 transcription after inducing perforant path LTP is that the inducing stimuli are distributed over time (10 min in a typical perforant path LTP experiment). Thus, it was of interest to assess the timing of MAP kinase activation with respect to $A r c / A r g 3.1$ induction after a more temporally discrete stimulus. In this regard, a relatively brief physiological event that strongly induces Arc transcription in dentate granule cells is an electroconvulsive seizure (ECS). Previous studies have revealed that a single ECS that lasts for $\sim 15$ sec strongly induces Arc transcription in dentate granule cells within $5 \mathrm{~min}$, and transcription continues for at least $4 \mathrm{~h}$ (Lyford et al. 1995). If MAP kinase 
1 Round of $400 \mathrm{~Hz}$

A
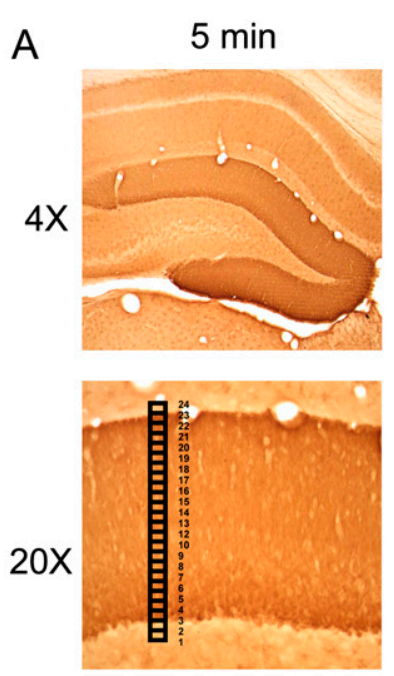

B

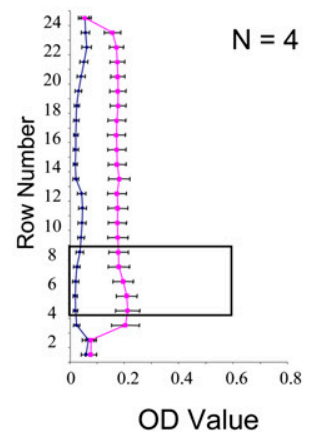

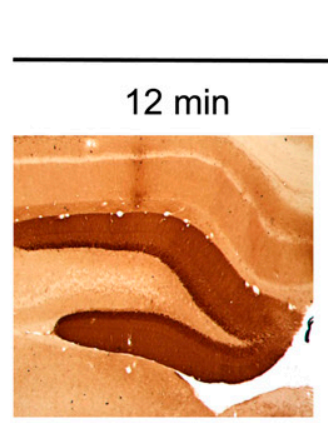
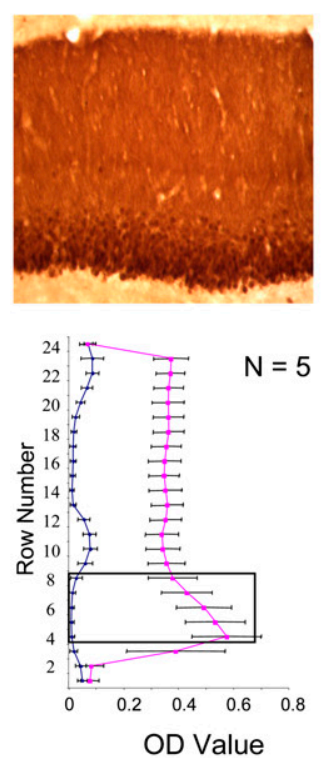

3 Rounds of $400 \mathrm{~Hz}$

$15 \min$
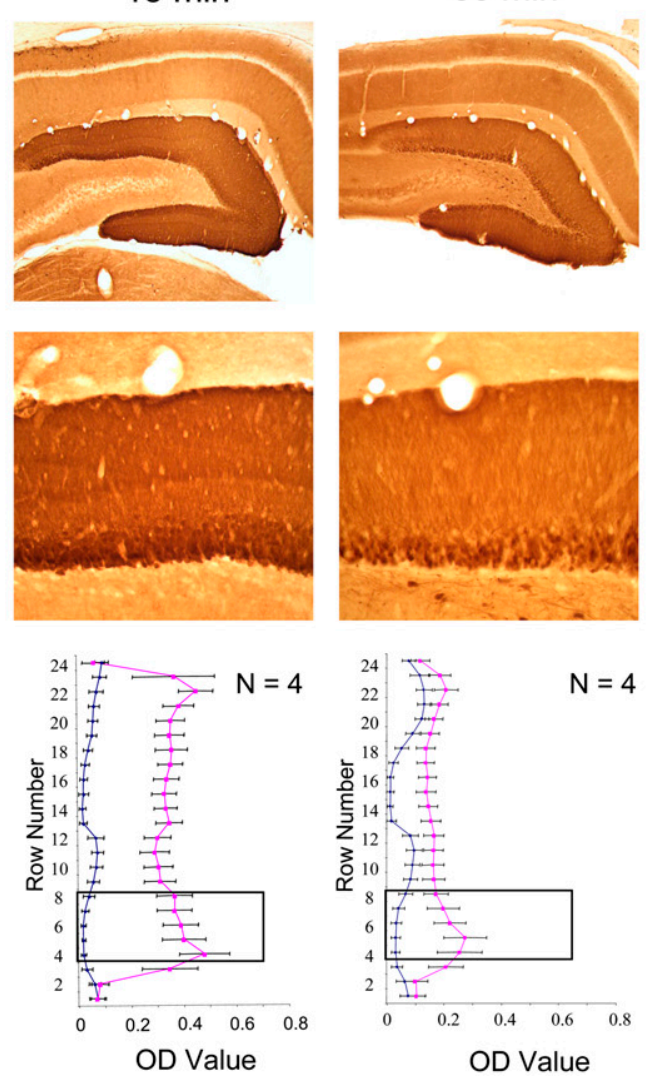
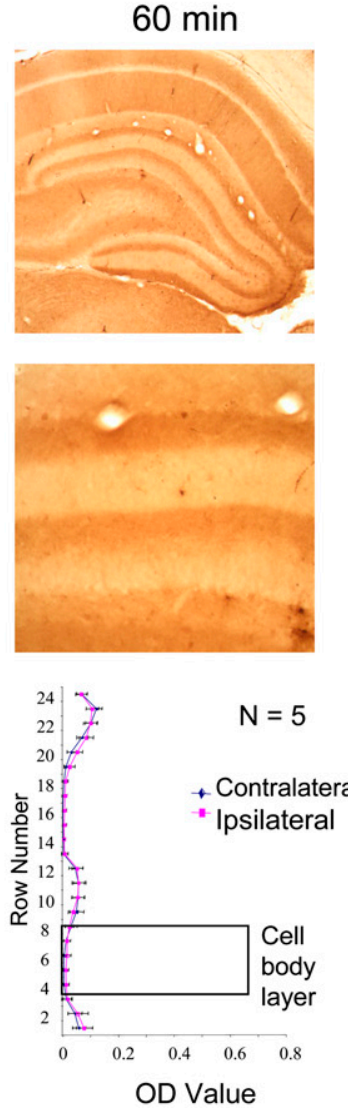

Figure 2. Time course of induction of ERK phosphorylation after induction of perforant path LTP. (A) Photomicrographs of immunostained sections from rats killed at various time points after one (5-min) or three (10-, 15-, 30-, and 60-min) rounds of HFS, as indicated at the top of each column. (Top) The dentate gyrus, with surrounding hippocampus, of the stimulated (ipsilateral) side. (Bottom) A higher magnification view of the dorsal blade of the dentate gyrus. Note that at 5 min after stimulation, no staining of p-ERK is seen in the nuclei, while at 10, 15, and 30 min, the cell bodies and nuclei are heavily stained. The pattern of staining at $60 \mathrm{~min}$ is comparable with what is seen on the control side (see Fig. 1A). (B) Graphs of the average optical density (OD) across the ipsilateral (stimulated) and contralateral (nonstimulated) dorsal blade at each time point. Each row number represents a particular row along the blade, as indicated in the 5 -min, $20 \times$ photo of $A$. Note that in the 5 -min group, staining density is relatively uniform across cell body and molecular layers, whereas in the 10- and 15-min groups, staining is more intense in the cell body layer.

activation is alone responsible for inducing Arc/Arg3.1 transcription, then there must be phosphorylation of nuclear p-ERK within 5 min after an ECS. Moreover, if continuing transcription also depends on MAP kinase activation, then MAP kinase activation should persist for as long as transcription continues.

To assess the time course of ERK activation after a single ECS, rats received an ECS and were perfused 5, 6, 8, 15, 25, and $\sim 60$ min post-seizure. A control animal was brought into the room in the same cage but did not receive an ECS. Tissue from all animals was stained for p-ERK in the same run. At 5 min after ECS, the trilaminar staining pattern typical of awake nonstimulated control rats (Fig. 4A-C) was replaced by a uniformly increased staining throughout the molecular layer and cell body layer of the dentate gyrus (Fig. 4D-F). Even at 5 min, nuclear staining for p-ERK was detectable (Fig. 4F). A similar staining pattern was seen in animals killed 6 and 8 min post-ECS (data not shown). By $15 \mathrm{~min}$ (Fig. 4G-I), the overall level of staining in the molecular layer was less so that the normal trilaminar staining pattern was discernable, but nuclei remained darkly stained. By 25 min (Fig. 4J-L), overall staining in the molecular layer was similar to control, and nuclear staining was less striking than at $15 \mathrm{~min}$. Finally, by $60 \mathrm{~min}$ (Fig. $4 \mathrm{M}-\mathrm{O})$, the pattern of staining in the molecular and granule layers was comparable with control. Thus, translocation of p-ERK to the nucleus appears to occur rapidly enough to account for initiating Arc transcription, but transcription continues long after MAP kinase activation has returned to control levels.

Our main focus was on dentate granule cells, but the pattern of MAP kinase activation in other hippocampal subregions warrants comment. At 5, 6, and 8 min post-ECS, the overall level of immunostaining increased in stratum oriens and radiatum of CA1-CA3, and even more so in the mossy fiber zone in stratum lucidum. Staining in the stratum lacunosum-moleculare in CA1 remained light. These increases in immunostaining were not evident by 15 min post-seizure except for the increased staining of mossy fibers, which remained high at $25 \mathrm{~min}$. Interestingly, despite the increases in p-ERK immunostaining in the dendritic layers (stratum radiatum and oriens), nuclei of pyramidal neurons in CA1-CA3 remained unstained at all time points. This is noteworthy because Arc transcription is induced only transiently in pyramidal neurons of CA1-CA3 at the same time that there is striking, long-lasting transcriptional induction in dentate granule cells. Neurons scattered throughout the hilus of the dentate gyrus also exhibited increased p-ERK immunostaining that was still evident 60 min post-seizure. Indeed, we have previously noted 

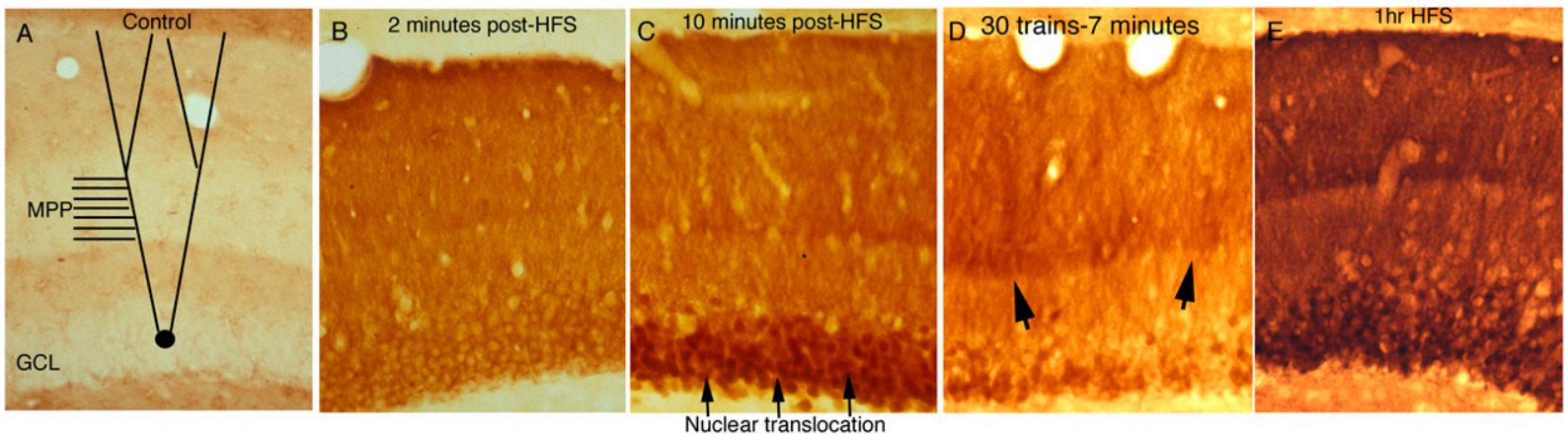

Figure 3. Time course and stimulation requirements for the nuclear localization of $p$-ERK after HFS of the perforant path. The photomicrographs illustrate the pattern of immunostaining for p-ERK in the control dentate gyrus and after various periods of HFS. $(A)$ Pattern of immunostaining in the unstimulated (control) dentate gyrus. The stick drawing illustrates the distribution of granule cell bodies and dendrites. (B) Five min after a single bout of 10 trains (which is not sufficient to induce persistent LTP), nuclei exhibited low levels of staining in comparison with the surrounding cytoplasm. (C) Ten min after three bouts of HFS (30 trains), nuclear staining is prominent. $(D)$ Immunostaining after 30 high-frequency trains delivered at a rate of $1 / 10$ sec over a period of $5 \mathrm{~min}$ without intervening test stimulation; the animal was perfused $\sim 2 \mathrm{~min}$ after the end of the stimulation period. Many nuclei exhibit high levels of immunostaining. $(E)$ Immunostaining after delivering HFS for $1 \mathrm{~h}$ at a rate of $1 / 10 \mathrm{sec}$.

increased p-ERK staining in this population of neurons $4 \mathrm{~h}$ postECS (Huang et al. 2007).

\section{Arc/Arg3.1 transcription and MAP kinase activation following exploration of a complex novel environment} Based on the postulated role of Arc/Arg3.1 in synaptic plasticity and memory consolidation, it was of interest to assess the relationship between MAP kinase activation and Arc/Arg3.1 transcription in dentate granule cells in response to experience. We chose a paradigm involving exposure to an enriched environment filled with toys. Rats were housed singly, and then brought into the toyfilled environment in groups of 2-4 so that there would also be novel social interactions. Previous studies have shown that after brief (5-min) exposure to an open field, Arc/Arg3.1 transcription in the CA1 region of the hippocampus peaks at $5 \mathrm{~min}$ and returns to near control levels by $15 \mathrm{~min}$ (Vazdarjanova et al. 2002). We reasoned that longer exposures to a complex novel environment would cause persistent induction of Arc/Arg3.1 transcription because animals continue to explore the novel environment and interact with toys and each other. Consistent with this prediction, $\operatorname{Arc/Arg3.1}$ mRNA levels were strikingly elevated in rats that were in the complex novel environment (Fig. 5 illustrates the pattern of labeling after $2 \mathrm{~h}$ of exploration). As reported previously (Temple and Steward 2003), the pattern of induction in the dentate gyrus involves an increase in the number of individual granule cells that are strongly labeled for Arc/Arg3.1 mRNA (Fig. 5B), and the density of $A r c / A r g 3.1$ positive granule cells was higher in the dorsal than in the ventral blade of the dentate gyrus. The increases seen here were more striking than seen after exposure to a simple open field, however (Temple and Steward 2003). Immunostaining for p-ERK revealed a moderate number of darkly stained granule cells in which nuclear staining was evident (Fig. 5E), but there were clearly fewer p-ERK positive cells than Arc positive granule cells.

To directly compare the number of $\operatorname{Arc/Arg3.1-positive~vs.~}$ p-ERK positive granule cells, sections from cases that had been exposed to the novel environment for $30 \mathrm{~min}, 1 \mathrm{~h}$, and $2 \mathrm{~h}$ were immunostained for p-ERK and Arc/Arg3.1 protein. We then counted the number of p-ERK positive vs. Arc/Arg3.1 positive granule cells per $100-\mu \mathrm{m}$ length of the granule cell layer, analyzing dorsal and ventral blades separately. The number of Arc/Arg3.1 positive granule cells increased with increasing time in the novel environment, whereas the number of pERK positive granule cells remained constant. Moreover, at all time points, there were significantly more Arc/Arg3.1 positive granule cells than p-ERK positive granule cells (Fig. 6). The differences were most striking at
$2 \mathrm{~h}$, at which time there were averages of $79.5 \pm 14.5$ and $68.2 \pm$ $19.8 \mathrm{Arc} / \mathrm{Arg} 3.1$ positive granule cells per $100-\mu \mathrm{m}$ length of the granule cell layer in the dorsal and ventral blade, respectively. In contrast, there were $8.3 \pm 0.5 .4$ and $6.4 \pm 3.9$ p-ERK positive granule cells per $100-\mu \mathrm{m}$ length $(P<0.002$ for the dorsal blade and $P<0.014$ for the ventral blade).

The most important comparisons are at the earliest time point, however, because of several factors. First, continuing exploration of the novel environment activates ERK and Arc/Arg3.1 in different populations of neurons at different times, as evidenced by the increases in the numbers of p-ERK and Arc/Arg3.1 positive neurons with longer periods of exploration. Both p-ERK and Arc provide some measure of the ensemble of neurons activated during a preceding time window, but defining a relationship between p-ERK and Arc requires knowing how long ERK remains phosphorylated after an inducing stimulus and how long it takes for sufficient amounts of Arc/Arg3.1 protein to be synthesized to be detectable. The persistence of ERK phosphorylation can be estimated from the experiments involving LTP induction or ECS, where immunostaining for p-ERK remains elevated in dentate granule cell nuclei for at least $15 \mathrm{~min}$, but fewer are labeled at $30 \mathrm{~min}$. Thus, some neurons that had been activated during the first few minutes of exploration in the novel environment might not still be p-ERK positive $30 \mathrm{~min}$ later. On the other side, it takes time for Arc/Arg3.1 protein to be synthesized after transcription is induced; even $30 \mathrm{~min}$ after initial exposure to the novel environment, immunostaining is quite light. It is virtually certain that many neurons in which Arc/Arg3.1 transcription had been activated during the final 15 min of a 30-min exploration period would not stain positively for Arc/Arg3.1 protein.

Given that there are approximately fivefold more Arc/Arg3.1 positive than p-ERK positive cells at $30 \mathrm{~min}$, it was of interest to assess whether ERK phosphorylation was activated in a larger number of neurons at the initial exposure to the novel complex environment. To assess this, rats were allowed to explore for $5 \mathrm{~min}$ and then anesthetized and perfused (the latter took $\sim 7 \mathrm{~min}$ ) so that the time of cessation of brain activity was $\sim 12$ min after the first exposure to the novel environment. In the four rats prepared in this way, the pattern of ERK phosphorylation was variable. The rat with the largest number of p-ERK positive granule cells had $10.6 / 100 \mu \mathrm{m}$ in the dorsal blade and $1.7 / 100 \mu \mathrm{m}$ in the ventral blade. The rat with the smallest number had 0.8 and $0.1 \mathrm{p}$-ERK positive neurons in the dorsal and ventral blade, respectively. The average in the four rats was $4.1 \pm 4.7$ and $1.4 \pm 1.6$ p-ERK positive granule cells in the dorsal and ventral blades, respectively, which is 


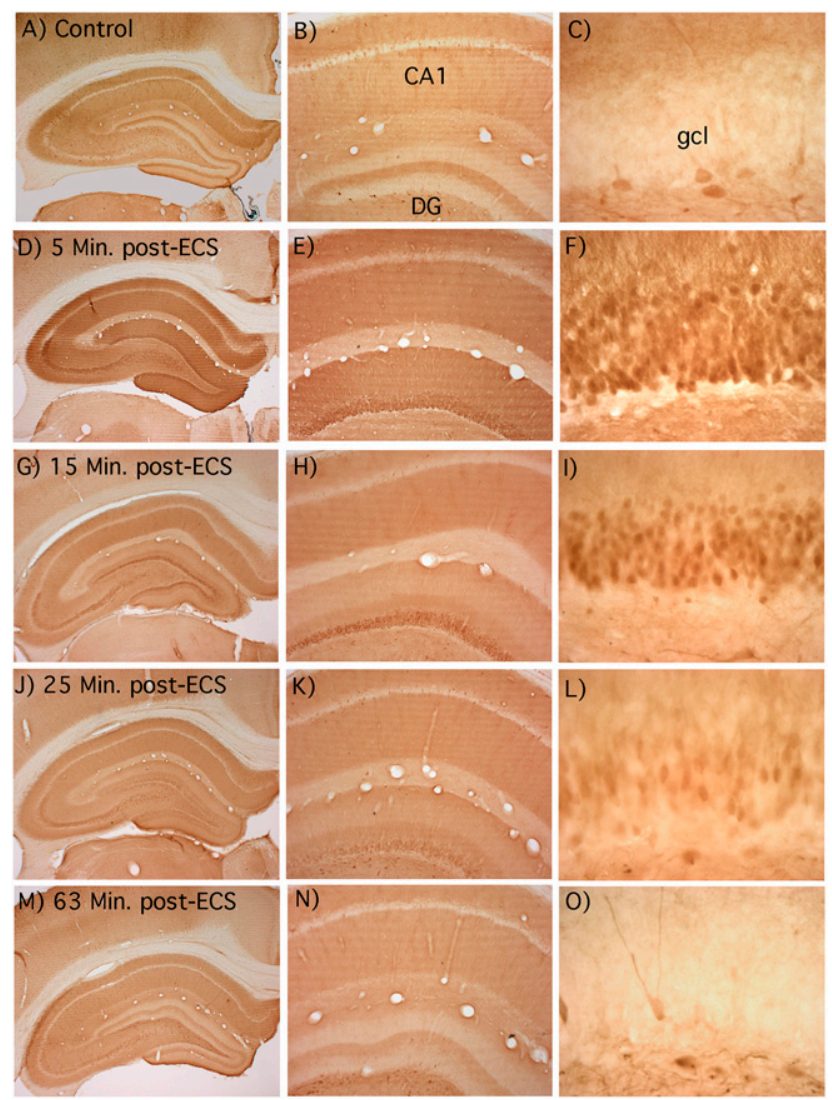

Figure 4. Time course of ERK activation after a single ECS showing the patterns of immunostaining in rats that received an ECS and were killed $5,15,25$, and $\sim 60$ min post-seizure and in a control animal that was brought into the room in the same cage but did not receive an ECS. $(A-C)$ Control; $(D-F) 5$ min post-ECS. Note that the tri-laminar staining pattern typical of awake nonstimulated control rats $(A-C)$ was replaced by a uniformly increased staining throughout the molecular layer and cell body layer of the dentate gyrus. Note also prominent nuclear staining for p-ERK in dentate granule cells. (G-l) Fifteen min post-ECS. The overall level of staining in the molecular layer was less, so the normal trilaminar staining pattern was discernable, but nuclei remained darkly stained. $(J-L)$ Twenty-five min post-ECS. Overall staining in the molecular layer was similar to control, and nuclear staining was less striking than at $15 \mathrm{~min}$. $(M-O)$ Sixty-three min post-ECS. The pattern of staining in the molecular and granule layers was comparable with the control, although neurons in the hilus continued to show high levels of p-ERK staining.

about the same number seen at $30 \mathrm{~min}$. Taken together, these results indicate that activation of $\mathrm{Arc} / \mathrm{Arg} 3.1$ transcription in dentate granule cells in response to experience cannot be accounted for entirely by MAP kinase activation.

The pattern of induction of Arc/Arg3.1 in the CA1 region of the hippocampus after $2 \mathrm{~h}$ of exploration was different than in the dentate gyrus in that Arc/Arg3.1 mRNA was detectable in virtually every pyramidal neuron (Fig. 5A,B). As in the dentate gyrus, Arc/Arg3.1 mRNA was also present throughout the dendritic layer indicating dendritic transport. At this time point, however, only a few pyramidal neurons stained positively for p-ERK (Fig. 5C,D). Some exhibited light cytoplasmic staining for p-ERK (Fig. 5F), but very few exhibited nuclear staining, and none exhibited the high levels of staining seen in dentate granule cells (cf. Fig. 5E). Given that brief (5-min) exposure to a novel open field triggers only transient Arc/Arg3.1 transcription in the CA1 region of the hippocampus (Vazdarjanova et al. 2002), there must be continuing transcriptional activation with continued exposure to the novel environment. This continuing transcription of $A r c / A r g 3.1$ in hippocampal pyramidal neurons must occur independently of MAP kinase activation.

\section{Activation of ERK phosphorylation in dentate granule cells depends on NMDA receptor activation}

To further test the relationship between MAP kinase activation and $A r c / A r g 3.1$ transcription in a paradigm in which a cause and effect relationship between MAP kinase activation and Arc/Arg3.1 transcription seemed most plausible (perforant path LTP), we used pharmacological agents to block particular molecular pathways. Previous studies have demonstrated that induction of Arc/Arg3.1 transcription, targeting of Arc/Arg3.1 mRNA to active synapses, and induction of LTP all depend critically on NMDA receptor activation during HFS of the perforant path (Steward and Worley 2001). This was demonstrated in experiments in which the NMDA receptor antagonists MK801 or APV were delivered locally via diffusion from recording micropipettes positioned in the dentate gyrus. Local delivery of either MK801 or APV blocked NMDA receptor-dependent synaptic currents activated during HFS of the perforant path, which in turn blocked the induction of IEG transcription in a local region surrounding the micropipette.

To determine whether MAP kinase activation requires NMDA receptor activation, we used the same approach as in previous studies in which recording micropipettes containing MK801 were positioned in the dentate gyrus 10-20 min before delivering HFS to the perforant path. In these experiments, we were particularly
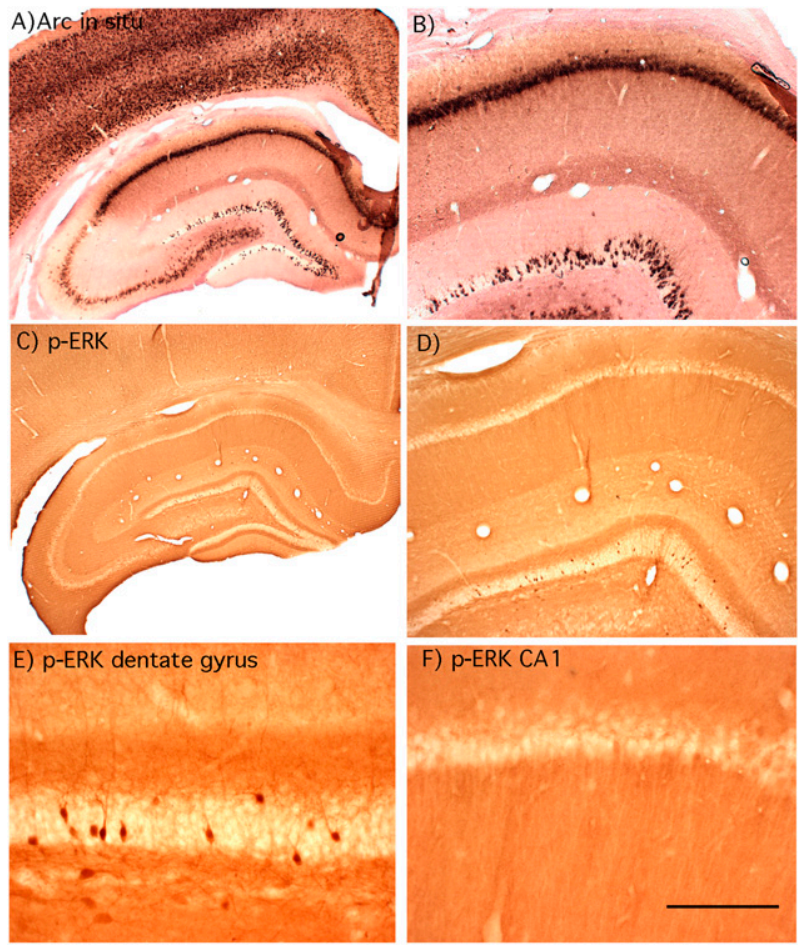

Figure 5. $\operatorname{Arc} / \operatorname{Arg} 3.1$ transcription and MAP kinase activation following 2-h exploration of a complex novel environment: Animal \#121107A. $(A, B)$ Pattern of labeling for Arc/Arg3.1 mRNA. Note the induction of Arc/Arg3.1 expression in many granule cells scattered through the dentate gyrus and that $\operatorname{Arc} / \operatorname{Arg} 3.1$ mRNA is induced in virtually every pyramidal neuron in CA1. ( $C-F)$ Pattern of immunostaining for $p$-ERK. Note that the laminated pattern of staining is generally comparable with that seen in awake cage control rats, but that neurons scattered through the granule cell layer exhibit high levels of $p$-ERK staining. Some hippocampal neurons in CA1 exhibit cytoplasmic staining for $p$-ERK, but very few exhibit nuclear staining, and none exhibit the high levels of staining seen in dentate granule cells. 

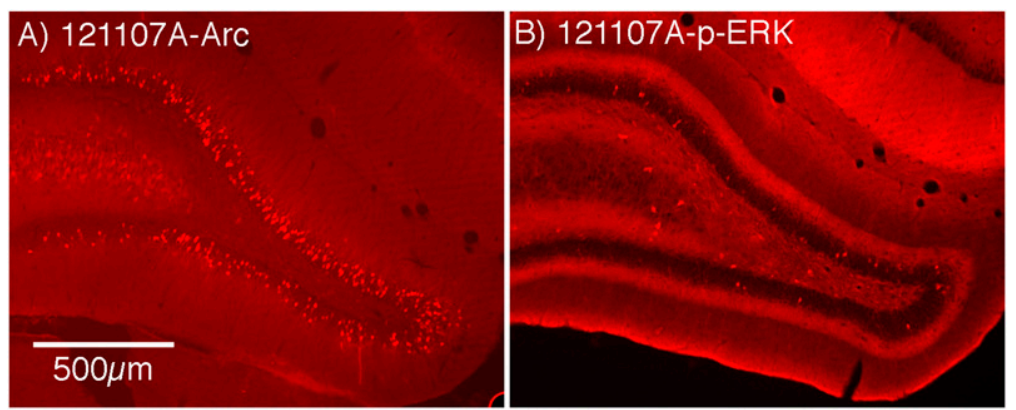

C)

Dorsal blade

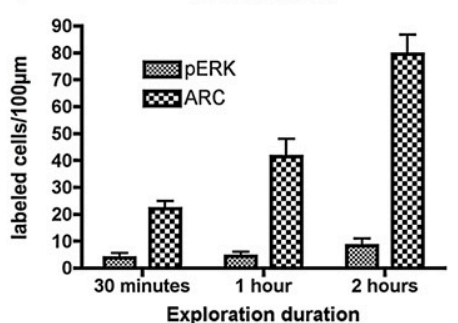

D)

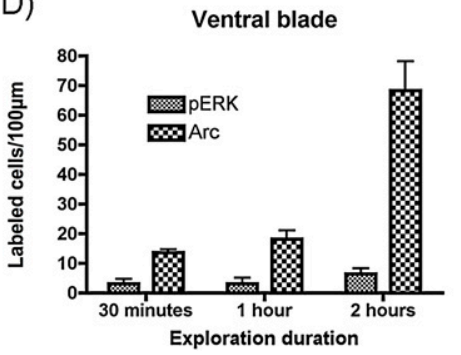

Figure 6. Comparison of Arc induction and MAP kinase activation following different periods of exploration of a complex novel environment. (A) Pattern of immunostaining for Arc protein after $2 \mathrm{~h}$ of exploration in the novel complex environment as revealed by immunofluorescence; note the large numbers of Arc-positive granule cells. This is from the same animal as shown in Figure 5 (\#121107A). (B) Pattern of immunostaining for p-ERK in the same animal; note that only a few granule cells exhibit staining for $\mathrm{p}$-ERK. $(C, D)$ Graphs illustrating counts of the number of p-ERK-positive $(C)$ and Arc-positive $(D)$ granule cells in the dorsal and ventral blade, respectively, after $30 \mathrm{~min}, 1 \mathrm{~h}$, and $2 \mathrm{~h}$ of exploration in the novel complex environment ( $n=4$ at $30 \mathrm{~min} ; n=3$ at $1 \mathrm{~h} ; n=4$ at $2 \mathrm{~h}$ ). Analyses by ANOVA revealed significant differences over time and in numbers of Arc positive vs. p-ERK positive cells both dorsal and ventral blades ( $P<0.001$ for both). Comparisons of numbers of $p$-ERK positive vs. Arc positive neurons by paired $t$-test revealed significant differences at all time points. (Thirty min dorsal blade: $t=4.62, P<$ 0.002 ; ventral blade: $t=4.98, P<0.02 ; 1 \mathrm{~h}$ : dorsal blade $t=4.92, P<0.04$; ventral blade: $\mathrm{t}=4.23, P<$ $0.05 ; 2 \mathrm{~h}$ : dorsal blade $t=10.58, P<0.002$; ventral blade: $t=5.231, P<0.014$.)

interested in whether diffusion from a micropipette created a persistent blockade, and so HFS was delivered for $2 \mathrm{~h}$, which is sufficient to induce persistent Arc/Arg3.1 expression and persistent ERK phosphorylation (Huang et al. 2007). When MK801 (10 mg/mL) was present in the micropipette, ERK phosphorylation was completely blocked in a region of about $1-2 \mathrm{~mm}$ in diameter surrounding the micropipette (Fig. 7A,B). Similar results were seen in six experiments. Assessment of Arc/Arg3.1 mRNA in nearby sections revealed that induction of $A r c / A r g 3.1$ transcription was blocked by MK801 in the same region in which ERK phosphorylation was blocked (for examples, see Steward and Worley 2001).

\section{Blockade of ERK activation attenuates Arc/Arg3.1 transcriptional activation and IEG protein expression during perforant path LTP}

If ERK phosphorylation is required for transcriptional activation of Arc/Arg3.1, then pharmacological blockade of ERK phosphorylation should block transcriptional activation of $\operatorname{Arc/Arg3.1}$. To directly test this hypothesis, we made local injections of the MEK inhibitor U0126 into the dentate gyrus prior to high-frequency stimulation of the perforant path and assessed the transcriptional activation of $\operatorname{Arc} / \operatorname{Arg} 3.1$. In one set of experiments, small volumes $(0.1-0.2 \mu \mathrm{L}$ ) of U0126 in 10\% dimethyl sulfoxide (DMSO)/0.9\% saline solution were injected via Hamilton microsyringes fitted with pulled glass capillaries. Physiological responses were recorded by attaching leads to the metal barrel of the Hamilton microsyringe. In other experiments, micropipette recording electrodes were filled with solutions of U0126 in 10\%DMSO/0.9\% saline.
Rats were prepared for acute neurophysiological experiments using salinefilled micropipettes to optimize stimulation parameters. Then, the saline electrode was replaced by a micropipette filled with U0126. Test responses were again collected, and if necessary, stimulus intensity was adjusted so as to generate population spikes of $4-8 \mathrm{mV}$. In most cases, response amplitude was reduced following positioning of the micropipette with U0126 so that higher stimulus intensities were required to elicit baseline responses of appropriate amplitude. After collecting 30-60 test responses, $3 \times 10$ high-frequency trains were delivered to induce LTP. In all cases, LTP was effectively induced; indeed, the magnitude of LTP was comparable with what we typically see in control experiments. As reported elsewhere (Huang et al. 2007) in five experiments with immunocytochemically verified blockade of ERK phosphorylation by U0126, the average increase in excitatory postsynaptic potential (EPSP) slope and population spike amplitude immediately after HFS at $400 \mathrm{~Hz}$ was $47 \pm 25 \%$ and $144 \pm 94 \%$, respectively (mean $\pm \mathrm{SD}$ ). In five control experiments carried out during the same time period, the average increase in EPSP slope and population spike amplitude immediately after HFS at $400 \mathrm{~Hz}$ was $43 \pm$ $24 \%$ and $304 \pm 209 \%$, respectively. Rats were perfused $30 \mathrm{~min}, 1 \mathrm{~h}$, and $4 \mathrm{~h}$ after the end of the stimulation. Thirty minutes is a sufficiently short period of time to assess p-ERK staining induced by the stimulation, allowing us to confirm that U0126 effectively blocked ERK phosphorylation. Longer time points allowed us to assess the net result of the stimulation with the MEK inhibitor on IEG expression.

Figure 8, A and B, illustrates an experiment in which 30 highfrequency trains were delivered (interspersed with test stimulation), test responses were collected for an additional $15 \mathrm{~min}$, and the rat was then perfused $\sim 30$ min after the start of HFS. Immunostaining for p-ERK revealed a complete blockade of ERK phosphorylation on the side that received HFS (Fig. 8B cf. with Fig. 1B). Interestingly, however, assessment of Arc/Arg3.1 mRNA levels by in situ hybridization revealed strong induction of $\operatorname{Arc} / \operatorname{Arg} 3.1$ transcription except in a very small region around the micropipette (Fig. 8D). Similar results were seen in four other experiments.

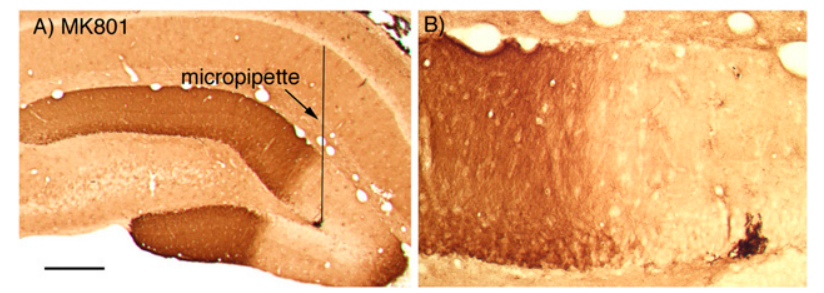

Figure 7. Blockade of ERK phosphorylation by MK801. Pattern of immunostaining for p-ERK when a micropipette filled with MK801 (10 $\mathrm{mg} / \mathrm{mL}$ in saline) was positioned in the dentate gyrus during the induction of perforant path LTP. Similar results were seen in six experiments. 


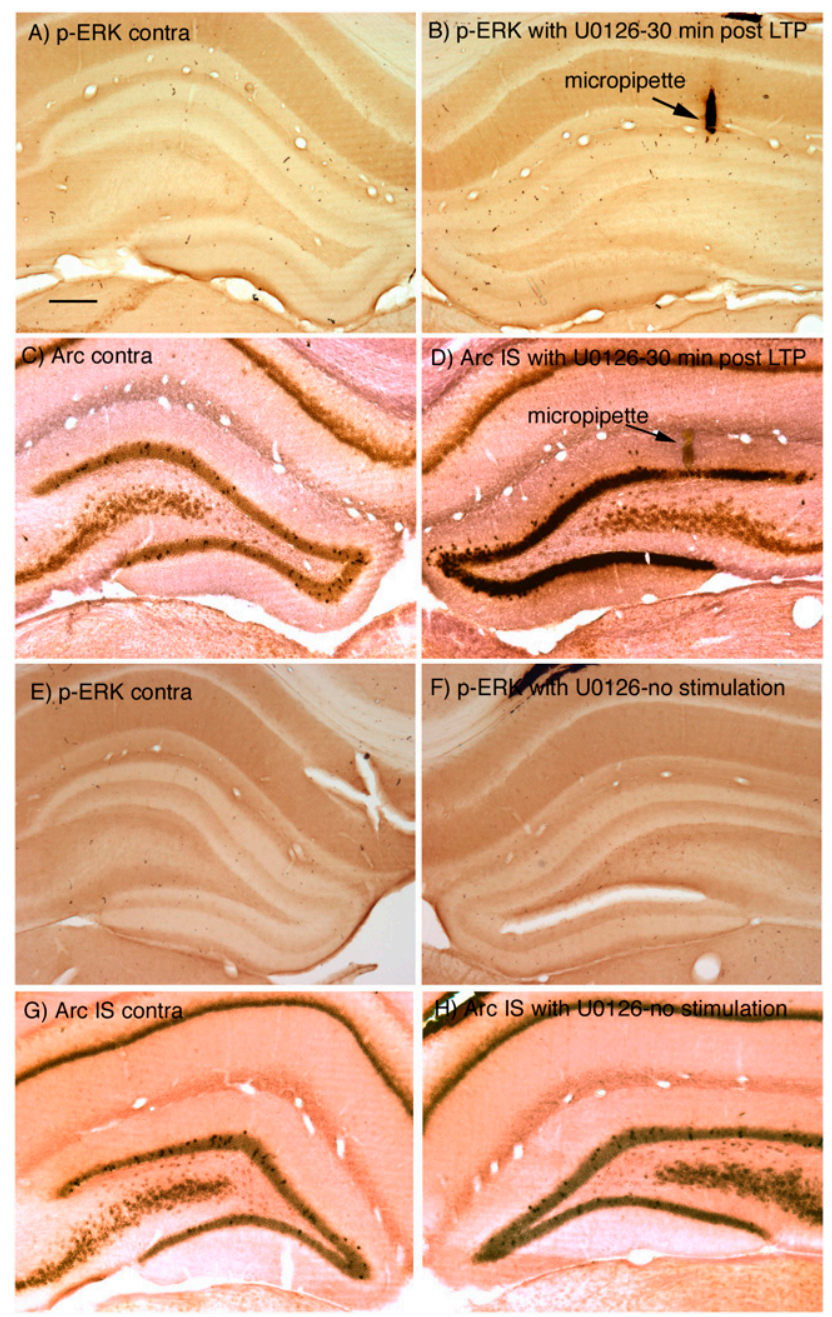

Figure 8. Blockade of ERK activation attenuates $\operatorname{Arc} / \operatorname{Arg} 3.1$ transcription. $(A-D)$ p-ERK immunostaining and Arc/Arg3.1 mRNA levels $30 \mathrm{~min}$ after LTP initiation when U0126 was present in the micropipette. $(A)$ p-ERK on the side contralateral to the stimulation; $(B)$ p-ERK on the stimulated side when U0126 was present in the micropipette. Note the blockade of ERK phosphorylation on the stimulated side (cf. Fig. 1A). The micropipette track is indicated by the arrow. (C) Arc/Arg3.1 mRNA on the side contralateral to the stimulation; (D) $\operatorname{Arc} / \operatorname{Arg} 3.1 \mathrm{mRNA}$ on the stimulated side when U0126 was present in the micropipette. $(E, F)$ Absence of induction of ERK phosphorylation when a U0126 micropipette was present in the dentate gyrus, but no stimulation was delivered. $(G, H)$ Absence of induction of $\operatorname{Arc} / \operatorname{Arg} 3.1$ mRNA when a U0126 micropipette was present in the dentate gyrus, but no stimulation was delivered. Scale bar, $250 \mu \mathrm{m}$, applies to all panels.

One possible complication in these experiments is that placement of the U0126-filled micropipette might activate IEG expression, especially because U0126 was dissolved in DMSO/saline. Accordingly, we carried out control experiments in which U0126-filled micropipettes were positioned in the dentate gyrus, and test responses were delivered for $30 \mathrm{~min}$. As illustrated in Figure 8, E-F, placement of the U0126-filled micropipette did not trigger ERK phosphorylation. The only alteration in p-ERK immunostaining was that a few neurons in the hilus exhibited p-ERK staining. Also, there was no induction of Arc/Arg3.1 mRNA transcription in the area surrounding the U0126-filled micropipette (Fig. 8H). Control injections of $0.1-0.2 \mu \mathrm{L}$ of vehicle (10\% DMSO) also had no effect on ERK phosphorylation (not shown).
Nonradioactive in situ hybridization (NRISH) was used for the experiments above because immunocytochemistry can be done on adjacent sections to reveal the area in which ERK phosphorylation is blocked. NRISH is not ideal for quantitative analysis of the extent of Arc/Arg3.1 induction and blockade, however, because deposition of reaction product is nonlinear. Accordingly, to quantitatively assess the degree of blockade of $\mathrm{ArC} /$ Arg3.1 induction by U0126, we carried out experiments in which Arc/Arg3.1 mRNA was assessed with fluorescent in situ hybridization (FISH). We first assessed $\operatorname{Arc} / \operatorname{Arg} 3.1 \mathrm{mRNA}$ by FISH in three control rats in which LTP was induced by delivering $3 \times 10$ trains, and rats were killed $30 \mathrm{~min}$ after the start of the HFS. As expected, Arc/Arg3.1 mRNA fluorescence was strikingly increased on the stimulated side (Fig. 9A). Then, three rats were prepared as above with a recording electrode with U0126 positioned in the dorsal blade of the dentate gyrus, LTP was induced by delivering $3 \times 10$ trains, and rats were killed 30 min later. As above, there was clear attenuation of $\mathrm{Arc} / \mathrm{Arg} 3.1$ induction in the dorsal blade in the area surrounding the U0126-filled micropipette, whereas Arc/Arg3.1 was strongly induced in the ventral blade (Fig. 9C). To quantify the blockade, levels of Arc/Arg3.1 mRNA fluorescence were assessed in the dorsal and ventral blade at the injection site, and in sections $\sim 1.5 \mathrm{~mm}$ rostral to the injection. Arc/Arg3.1 mRNA fluorescence was only slightly higher than the control side in the dorsal blade at the injection site, indicating near-complete blockade. Arc/Arg3.1 mRNA fluorescence was increased in the ventral blade at the level of the injection, although not as much as in rostral sections distant from the injection. Comparisons of the extent of the increase in $\mathrm{Arc} / \mathrm{Arg} 3.1 \mathrm{mRNA}$ fluorescence in control rats vs. rats that received U0126 revealed that Arc/Arg3.1 mRNA levels were significantly lower in both the dorsal blade near the U0126-containing micropipette and in the ventral blade of the same section $(P<$ 0.004 for both). Thus, U0126 blocks Arc/Arg3.1 induction in a small area near the injection site and attenuates induction in areas 1-2 $\mathrm{mm}$ distant from the injection.

We have been unable to obtain satisfactory labeling with FISH in perfusion-fixed tissue, nor have we been able to obtain satisfactory p-ERK immunostaining in the unfixed tissue that is required for NRISH. Thus, it was not possible to assess the spatial extent of blockade of ERK phosphorylation in the animals prepared for FISH. Nevertheless, the NRISH/immunocytochemical data (Fig. 8) clearly indicates that Arc/Arg3.1 transcription is induced in areas in which pERK staining is comparable with the control side, indicating complete blockade.

Although U0126 caused only a small area of blockade of Arc/Arg3.1 transcription following HFS, immunocytochemical assessment of IEG protein expression revealed blockade of induction of Arc/Arg3.1 protein expression over a larger area of the dentate gyrus. This is illustrated in Figure 10, which is from a different experiment than illustrated in Figures 8 and 9. This experiment involved the identical paradigm as in Figure 8. A micropipette filled with U0126 was positioned in the dorsal blade of the dentate gyrus, LTP was induced by delivering 30 HFS trains, and the animal was perfused $\sim 30 \mathrm{~min}$ after the initiation of HFS. Sections were immunostained for p-ERK, Arc/Arg3.1 protein, and also c-fos protein. In this experiment, immunostaining for pERK on the stimulated side was slightly darker than on the control side, and there were a few granule neurons exhibiting nuclear staining for p-ERK, indicating that blockade of ERK phosphorylation was incomplete (Fig. 10B). Nevertheless, the induction of expression of both Arc/Arg3.1 protein (Fig. 10D) and c-fos protein (Fig. 10F,G) was strongly attenuated in the area surrounding the U0126-filled micropipette. Blockade of c-fos protein expression was complete in the dorsal blade of the dentate gyrus near the micropipette (Fig. $10 \mathrm{G}$ ) and almost complete in the ventral blade (Fig. 10H). A useful positive control is the strong induction of c-fos protein expression 

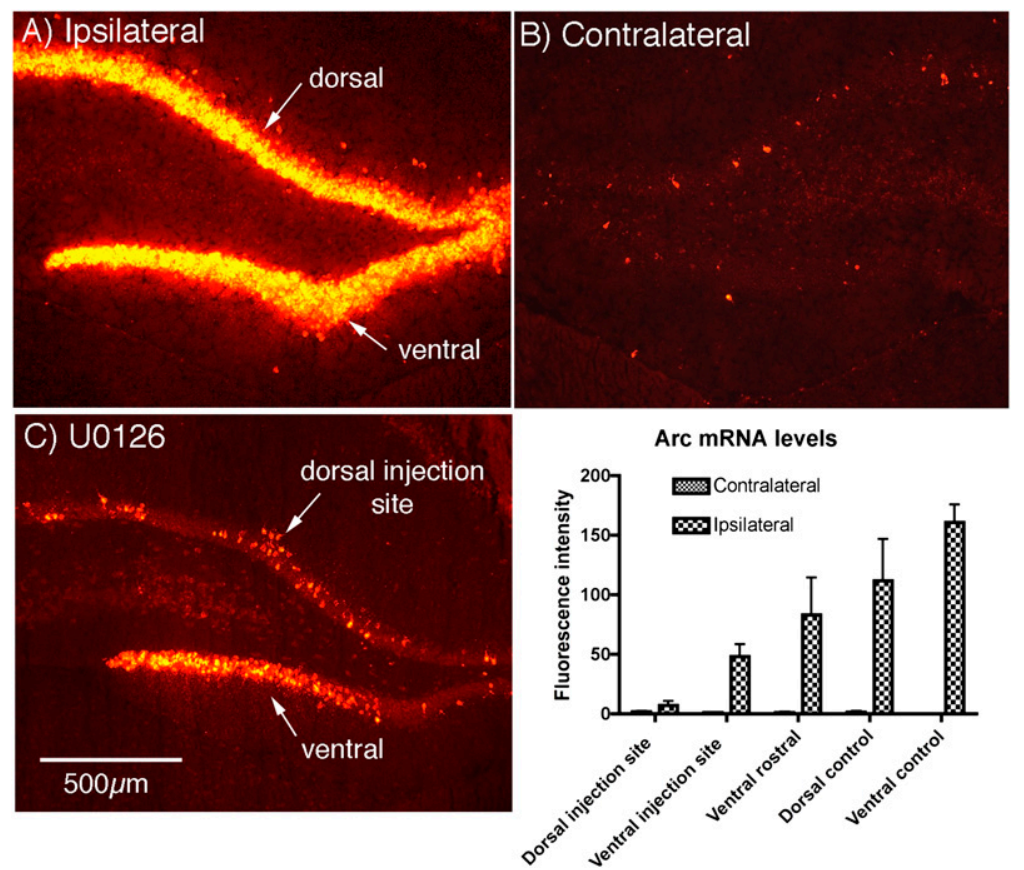

Figure 9. Quantitative assessment of U0126 blockade of $\operatorname{Arc} / \operatorname{Arg} 3.1$ induction using FISH. (A) Induction of Arc/Arg3.1 mRNA in the dentate gyrus $30 \mathrm{~min}$ after inducing perforant path LTP. (B) Contralateral (control) side of the same animal. (C) Attenuation of induction of $\operatorname{Arc} / \operatorname{Arg} 3.1 \mathrm{mRNA}$ in the area surrounding a U0126-filled micropipette. Note reduced labeling for Arc/Arg3.1 mRNA throughout the dorsal blade and strong induction in the ventral blade at a distance from the micropipette tip. The small cluster of $\operatorname{Arc} / \operatorname{Arg} 3.1$-positive granule cells is at the tip of the micropipette. Similar small clusters of Arc/Arg3.1 positive neurons are usually seen at the tip of a recording micropipette. The graph illustrates the results of a quantitative analysis of $\operatorname{Arc} / \operatorname{Arg} 3.1 \mathrm{mRNA}$ fluorescence at the injection site in the dorsal blade (dorsal injection site), the ventral blade of the same section (ventral injection site), in the ventral blade $\sim 1-2 \mathrm{~mm}$ rostral to the micropipette, and in dorsal and ventral blades of sections from three rats that received HFS in the absence of U0126 (dorsal control and ventral control). Also shown are the values for average fluorescence intensity in similar locations on the contralateral side of the brain that did not receive stimulation. Statistical comparisons were by $t$-test $(n=3$ control; $n=3$ treated with U0126); $\operatorname{Arc} / \operatorname{Arg} 3.1$ mRNA levels were significantly lower in both the dorsal blade near the U0126containing micropipette and in the ventral blade of the same section $(P<0.004$ for both).

in anterior portions of the hippocampus distant from the U0126 injection (Fig. 10I).

The same result was seen in the three animals illustrated in Figure 9. Sections near the ones assayed for Arc/Arg3.1 mRNA were immunostained for Arc/Arg3.1 protein. Quantitative analysis of fluorescence revealed blockade of Arc/Arg3.1 protein induction in both dorsal and ventral blades at the level of the U0126 injection (Fig. 11) whereas induction of $\mathrm{Arc} / \mathrm{Arg} 3.1 \mathrm{mRNA}$ in the same cases was blocked only in the dorsal blade very near the injection (cf. Fig. 9). Thus, the basic result, blockade of Arc/Arg3.1 protein synthesis over a larger area than the blockade of Arc/Arg3.1 mRNA transcription, was seen in four out of four rats.

\section{Discussion}

The goal of the present study was to explore the degree to which MAP kinase activation is critical for inducing Arc/Arg3.1 transcription in dentate granule cells in vivo in response to perforant path LTP and other events that induce $\operatorname{Arc} / \operatorname{Arg} 3.1$ expression. Our results confirm previous studies demonstrating striking ERK phosphorylation in dentate granule cells following induction of perforant path LTP (Davis et al. 2000); this activation depends on the same synaptic signals that are necessary to induce Arc/Arg3.1 transcription and LTP (namely, NMDA receptor activation). ERK phosphorylation is also induced by other physiological events that induce Arc/Arg3.1 transcription, including ECS and explora- tion of a complex novel environment. Nevertheless, other factors play a role because Arc/Arg3.1 is strongly induced in many neurons by behavioral experience, whereas far fewer exhibit p-ERK activation. Moreover, induction of $\mathrm{Arc} / \mathrm{Arg} 3.1$ transcription following HFS of the perforant path occurs in areas in which ERK phosphorylation is blocked by local delivery of the MEK inhibitor U0126. In what follows, we discuss the implications of our findings for understanding the mechanism that mediates induction of Arc/Arg3.1 expression in dentate granule cells in response to different physiological events.

\section{Role of MAP kinase in activating Arc/Arg3.1 transcription following induction of perforant path LTP}

The striking activation of ERK phosphorylation in granule cells and appearance of p-ERK to the nucleus following HFS of the perforant path is consistent with a role for MAP kinase signaling in activating the transcription of $\mathrm{Arc} / \mathrm{Arg} 3.1$ and other IEGs. Moreover, both ERK phosphorylation and induction of Arc/Arg3.1 transcription depend on NMDA receptor activation. Within minutes after the first episode of robust synaptic activity, staining for p-ERK is evident in nuclei. In considering timing, it is important to recall that induction of $\mathrm{Arc} / \mathrm{Arg} 3.1$ transcription after perforant path LTP is very rapid; for example, transcriptional foci are evident within nuclei with $5 \mathrm{~min}$ (Steward et al. 2007). The signal that triggered this transcription must have occurred even earlier. If nuclear p-ERK is responsible, it must activate transcription in the earliest stages of its progressive appearance in nuclei.

One hint that the earliest phase of Arc/Arg3.1 transcription may be triggered by something other than p-ERK is the fact that Arc/Arg3.1 transcription is still induced in areas in which ERK phosphorylation is blocked by U0126. It is noteworthy that a previous study (Davis et al. 2000) reported that transcriptional activation of zif268 is blocked by a different MEK inhibitor (SL327). This could mean that zif268 transcription depends on MAP kinase, whereas Arc transcription does not. Importantly, however, Davis et al. (2000) also report that SL327 blocked the induction of perforant path LTP, whereas in our experiments, U0126 blocked ERK phosphorylation but did not block the induction of perforant path LTP (see also Huang et al. 2007). It is noteworthy that SL327 also caused a decrease in basal ERK phosphorylation prior to LTP induction. In a more recent study published after our experiments were completed, local infusion of U0126 45 min prior to HFS blocked Arc/Arg3.1 protein induction as measured by Western blot and caused LTP to decay to near baseline levels within about 20 min after induction (Panja et al. 2009). These experiments involved infusion of $0.6 \mu \mathrm{L}$ of U0126, whereas the maximal volume injected in our studies was $0.2 \mu \mathrm{L}$. The larger volume might have affected ERK phosphorylation over a wider area. In our experiments, the recording electrode was positioned in the dorsal blade, and ERK activation was blocked in 

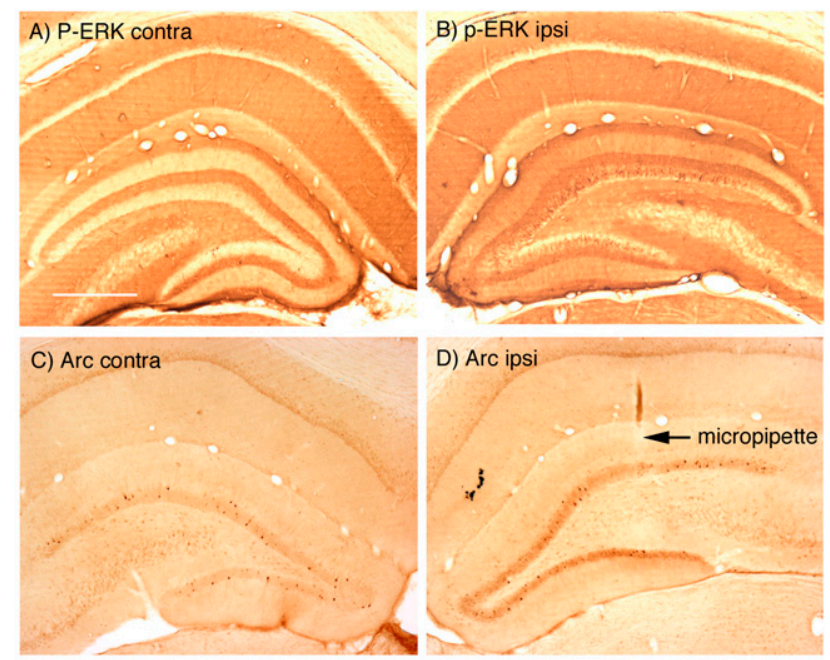

D) Arc ipsi
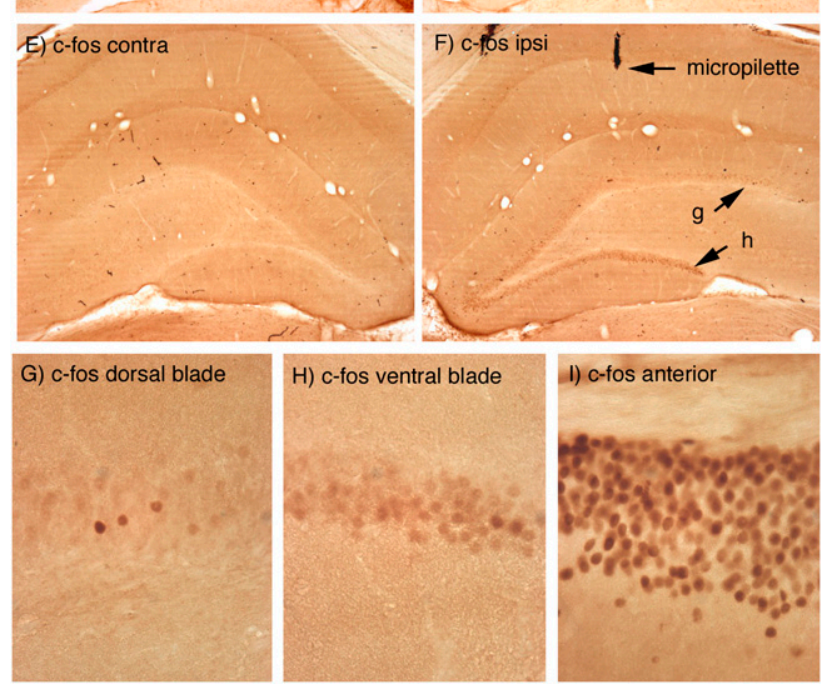

Figure 10. Blockade of ERK activation blocks induction of IEG protein expression. The panels illustrate the pattern of immunostaining for $p$-ERK, Arc/Arg3.1 protein, and c-fos protein $30 \mathrm{~min}$ after HFS of the perforant path when UO 126 was present in the recording micropipette. $(A, B)$ Immunostaining for p-ERK contralateral $(A)$ and ipsilateral $(B)$ to the HFS. Note the blockade of ERK phosphorylation on the stimulated side (cf. Fig. 1A). $(C, D)$ Immunostaining for Arc/Arg3.1 protein contralateral (C) and ipsilateral $(D)$ to the HFS. Note the blockade of induction of Arc/Arg3.1 protein, especially in the dorsal blade of the dentate gyrus. $(E, F)$ Immunostaining for c-fos contralateral $(E)$ and ipsilateral $(F)$ to the HFS. Note the blockade of induction of c-fos protein, especially in the dorsal blade of the dentate gyrus. The high-power micrographs in $G$ and $H$ are taken at the sites indicated by " $\mathrm{g}$ " and " $\mathrm{h}$ " in $F$. (I) Strong induction of c-fos protein expression in the anterior portion of the hippocampus distant from the U0126-containing micropipette. Scale bar in $A, 500 \mu \mathrm{m}$, applies to $A-F$.

the dorsal blade near the recording electrode but was not completely blocked in the ventral blade. Hence, the lack of abrogation of LTP in our experiments could be due to volume conduction of responses from sites outside the zone of blockade.

Panja et al. (2009) also showed that infusion of U0126 $10 \mathrm{~min}$ after LTP induction also caused LTP to decay to near baseline levels within about $20 \mathrm{~min}$. Moreover, in rats that received infusions of U0126 10 min after HFS, the induction of both Arc/Arg3.1 protein and mRNA levels were also blocked. These findings suggest that ERK activation is critical for the maintenance of transcriptional activation and for the maintenance of LTP. Taking all the evidence together, the simplest interpretation is that ERK plays a major role in maintaining transcriptional activation after an inducing stimulus and in Arc/Arg3.1 protein synthesis but that some other signal participates in the earliest phases of transcriptional activation.

What other candidate signal transduction cascades could be responsible for inducing Arc/Arg3.1 transcription? Possible candidates include increases in intranuclear calcium following entry through NMDA receptors and/or L-type $\mathrm{Ca}^{2+}$ channels (for a recent review, see Greer and Greenberg 2008) or signal transduction pathways activated by cytoplasmic calcium (one or more $\mathrm{Ca}^{2+} /$ calmodulin-dependent protein kinase II [CaM] kinases). This would be consistent with recent reports that Arc transcription in neurons in culture is regulated by CREB, SRF, and MEF2 (Kawashima et al. 2009) as well as another novel transcription factor (Pintchovski et al. 2009). Thus, activation of Arc transcription in response to different physiological events in vivo may be mediated by different signaling pathways operating in parallel.

Although induction of Arc/Arg3.1 transcription is not completely blocked by U0126, the mRNA that is transcribed in areas lacking p-ERK is apparently not effectively translated because expression of both Arc/Arg3.1 and c-fos protein are strongly inhibited in areas in which ERK phosphorylation is blocked. Panja et al. (2009) also demonstrated strong blockade of Arc/Arg3.1 protein synthesis by U0126. This is consistent with other evidence that MAP kinase is involved in regulating many other events in neurons including protein synthesis (for example, see Klann and Dever 2004).

\section{Relationship between MAP kinase activation and Arc/Arg3.1 transcription after ECS and after exploration of a novel complex environment}

Arc/Arg3.1 transcription is induced in dentate granule cells within 2 min after an ECS (Guzowski et al. 1999). Here we show that ECS triggers rapid ERK phosphorylation in dentate granule cells and p-ERK staining in granule cell nuclei within $5 \mathrm{~min}$. Thus, it is plausible that MAP kinase activation is responsible for triggering the early phase of $\operatorname{Arc} / \operatorname{Arg} 3.1$ transcription after ECS. At the same time, however, Arc/Arg3.1 transcription continues for hours, whereas MAP kinase activation returns to control levels within 1 h. Thus, the later stages of Arc/Arg3.1 transcription must be driven by something other than persistent MAP kinase activation.

The pattern of activation of ERK phosphorylation vs. induction of Arc/Arg3.1 transcription following exploration in a novel complex environment also suggests that MAP kinase is not the only mediator. The pattern of activation after $30 \mathrm{~min}$ of exploration is particularly informative. Immunostaining for p-ERK persists for at least $30 \mathrm{~min}$ after LTP and seizures; thus, if ERK phosphorylation was the principal activator of Arc/Arg3.1 transcription, then roughly the same number of granule cells should be labeled for p-ERK and Arc $30 \mathrm{~min}$ after the initial exposure to the novel environment. This is especially true because levels of Arc/Arg3.1 protein are just beginning to increase and the overall level of staining is light so that the number of Arc/Arg3.1 positive neurons may be underestimated. In fact, however, there were far more Arc/Arg3.1 positive than p-ERK positive granule cells at $30 \mathrm{~min}$ and also at the longer time points. Moreover, there was no evidence for a larger number of p-ERK positive granule cells when rats were killed after $5 \mathrm{~min}$ of exploration. These discrepancies suggest that some signal other than activation of MAP kinase is responsible for activating Arc/Arg3.1 transcription in most granule cells.

It is noteworthy that $\mathrm{ArC} / \mathrm{Arg} 3.1$ transcription was activated in a larger number of granule cells here than in previous studies involving exposure to an open field without toys (Temple and Steward 2003; see also Chawla et al. 2005). This may be due to the large variety of items in the enriched environment allowing a variety of different learning experiences. 

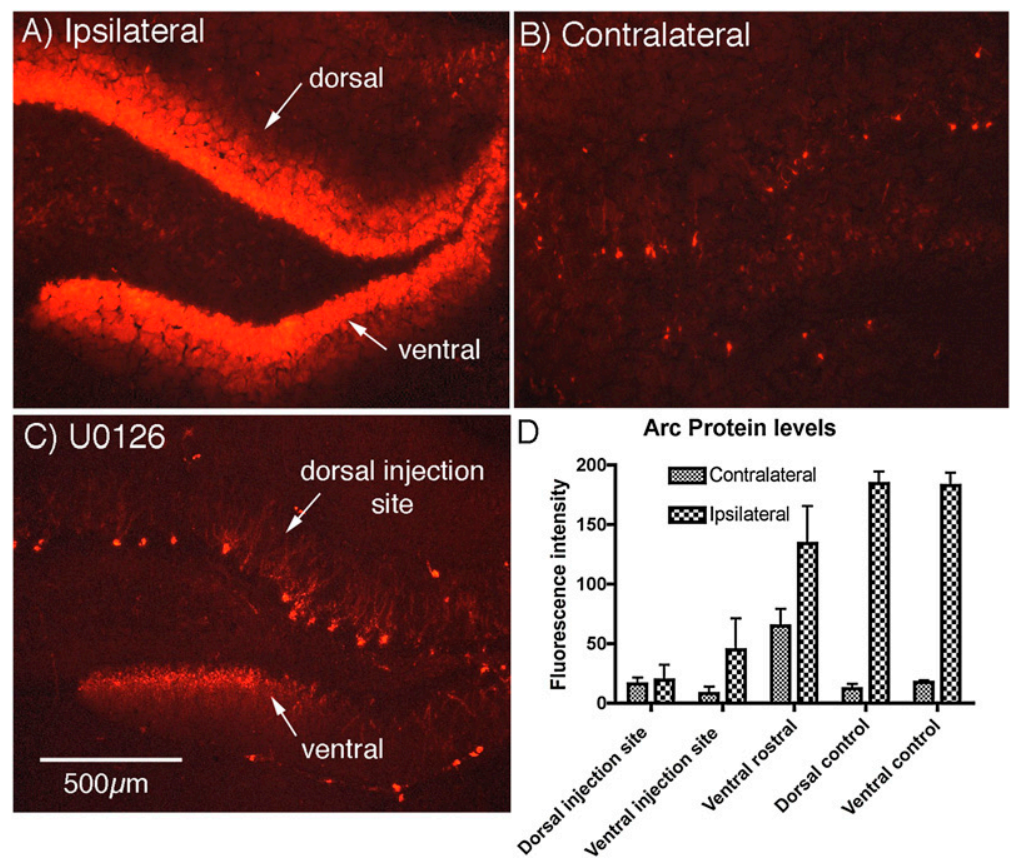

Figure 11. Quantitative assessment of U0126 blockade of Arc/Arg3.1 protein induction using immunofluorescence. The graph illustrates the results of a quantitative analysis of Arc immunofluorescence at the injection site in the dorsal blade (dorsal injection site), the ventral blade of the same section (ventral injection site), and in dorsal and ventral blades of sections from three rats that received HFS in the absence of U0126 (dorsal control and ventral control). These are the same cases in which Arc mRNA levels were quantitatively assessed in Figure 9. Also shown are the values for average fluorescence intensity in similar locations on the contralateral side of the brain that did not receive stimulation. Quantitative analysis of fluorescence revealed blockade of Arc induction in both dorsal and ventral blades at the level of the U0126 injection, whereas induction of Arc mRNA in the same cases was blocked only in the dorsal blade very near the injection (cf. Fig. 11 with Fig. 9).

\section{Relationship between MAP kinase and $\operatorname{Arc} / \operatorname{Arg} 3.1$ transcription in other neuron types}

Our experiments focused on the signal transduction pathways that mediate transcriptional activation of $\operatorname{Arc} / \operatorname{Arg} 3.1$ in dentate granule cells, but the data are also informative about the relationship between MAP kinase activation and Arc transcription in other cell types. In particular, exploration of a complex novel environment strongly induced Arc/Arg3.1 mRNA in the majority of pyramidal neurons in the CA1 region of the hippocampus, but these neurons did not show strong cytoplasmic staining for p-ERK, and very few exhibited nuclear staining. These results suggest that a signal transduction pathway other than MAP kinase mediates transcriptional activation of $\operatorname{Arc} / \operatorname{Arg} 3.1$ in hippocampal pyramidal neurons.

At the same time, however, studies of hippocampal slices have provided evidence that NMDA receptor activation triggers ERK phosphorylation in CA1 neurons. Other studies have revealed that ERK phosphorylation in hippocampal neurons is also induced by other stimuli that trigger long-lasting synaptic modifications including behavioral training (Sweatt 2001; Morozov et al. 2003). In these situations, ERK phosphorylation requires many of the same signaling components that are necessary for long-term changes in synaptic efficacy (Dudek and Fields 2001; Patterson et al. 2001; Sweatt 2001). Moreover, in at least some situations, inhibition of ERK signaling attenuates or inhibits some forms of synaptic plasticity and memory (Coogan et al. 1999; Selcher et al. 1999; Schafe et al. 2000). Thus, the relative roles of MAP kinase vs. other signaling pathways in activating Arc/Arg3.1 transcription in different types of neurons and in response to different physiological events remains to be explored.

\section{Materials and Methods}

\section{Electrophysiology techniques}

Experiments were carried out using adult male Sprague-Dawley rats. Animals were anesthetized via intraperitoneal injections of $20 \%$ urethane $(500 \mathrm{mg} / \mathrm{kg}$ body weight) given approximately every $10 \mathrm{~min}$ until the animal was totally unresponsive to tail pinch. Rats were positioned in a stereotaxic apparatus, and burr holes were placed in the skull to allow placement of stimulating and recording electrodes. An insulated monopolar stimulating electrode was positioned stereotaxically at $4.0 \mathrm{~mm}$ lateral to the midline and $1.0 \mathrm{~mm}$ anterior to the transverse sinus. The depth of the stimulating electrode was adjusted so as to maximally activate the medial perforant path (MPP) originating from the medial entorhinal cortex (EC) - usually 3-4 $\mathrm{mm}$ below the cortical surface. Glass recording electrodes filled with $0.9 \%$ saline, or with various pharmacological agents (see below), were positioned at $1.5-2.0 \mathrm{~mm}$ lateral to the midline and $3.5 \mathrm{~mm}$ posterior to bregma. Electrodes were positioned in the dorsal blade of the dentate gyrus so as to record field potentials from the cell body layer.

\section{Stimulation paradigm}

After positioning the stimulating and recording electrodes, stimulus intensity was set so as to evoke a population spike of $\sim 3-6 \mathrm{mV}$. Single test pulses were delivered at a rate of $1 / 10 \mathrm{sec}$ at the same intensity for $10 \mathrm{~min}$ to determine baseline response amplitude, measuring the slope of the population EPSP and amplitude of the population spike. In experiments in which a drug was allowed to passively diffuse into the dentate gyrus, a saline-filled electrode was first positioned so as to record responses prior to drug delivery. The saline electrode was then exchanged for one containing the pharmacological agent, and responses were again collected to determine the effect of the drug alone. Following these pre- and post-drug baseline recordings, three rounds of HFS were given, with each round consisting of 10 trains of eight pulses at $400 \mathrm{~Hz}$ and each train given at a rate of $1 / 10 \mathrm{sec}$. After each bout of HFS, a round of 10 test pulses was given to determine the extent of potentiation of synaptic responses. After the third round of test pulses, either test stimulation or HFS stimulation was continued as described in the Results.

\section{Local delivery of pharmacological agents}

Recording micropipette electrodes were pulled glass micropipettes broken off so that the internal diameter was $\sim 30-70 \mu \mathrm{m}$. This allowed diffusion of drug from the electrode to the surrounding area in the dentate gyrus. Depending on the drug, and whether the stock had to be dissolved in DMSO first, the diffusion from the tip of the electrode is between $0.2 \mathrm{~mm}^{2}$ and $2 \mathrm{~mm}^{2}$ (Steward and Worley 2001). The commercially available pharmacological agents included the NMDA receptor antagonist MK801 (10 mg/mL, Sigma) and the MEK inhibitor U0126 (20 $\mu \mathrm{M}$ in $10 \%$ DMSO/0.9\% saline, Sigma or Tocris). In some of the experiments involving U0126, a 10- $\mu \mathrm{L}$ Hamilton injection syringe fitted with a glass electrode tip was used instead of a standard glass electrode, and small volumes of the drug solution $(0.1-0.2 \mu \mathrm{L})$ were injected over a period of $5 \mathrm{~min}$. An additional 5 min of recovery was then allowed where no test pulses were given. 


\section{Electroconvulsive seizures}

A single ECS was induced in young adult female Sprague-Dawley rats as described previously (Wallace et al. 1998). Current was passed transcranially ( $40 \mathrm{~mA}$ for $0.5 \mathrm{sec}$ ) via ear clip electrodes resulting in a generalized tonic/clonic seizure that lasted $\sim 15 \mathrm{sec}$. Animals were allowed to survive for 5, 6, 8, 15, 25, and $63 \mathrm{~min}$ after the ECS. A control animal was brought into the room in the same cage but did not receive an ECS. Tissue from animals at all time points, including the control, was stained in the same run.

\section{Exposure to a novel enriched environment}

Young adult female Sprague-Dawley rats were exposed to a novel toy-filled environment for $5 \mathrm{~min}$ ( $n=4$ rats), $30 \mathrm{~min}$ ( $n=3 \mathrm{rats}), 1 \mathrm{~h}$ ( $n=3$ rats), or $2 \mathrm{~h}$ ( $n=4$ rats). Prior to exposure, the animals were individually housed, so the exposure to the novel environment also involved novel social interactions. The enriched environment cage was made of Plexiglas and was $2 \mathrm{~m}$ long $\times 1 \mathrm{~m}$ wide $\times 1 \mathrm{~m}$ high. The cage consisted of two floors and included multiple opportunities for exercise and exploration (running wheels, climbing frames, tubes, and children's plastic toys that the rats could crawl into). Water and food were placed at opposite sides of the cage. Of the four rats that were allowed to explore for $2 \mathrm{~h}$, two explored the enriched environment in the morning just after light onset; the other two explored the enriched environment in the evening just after light offset. Animals were anesthetized and perfused with $4 \%$ paraformaldehyde immediately after the exploration period.

\section{Tissue preparation}

Rats were killed by a lethal injection of the anesthetic Euthasol or sodium pentobarbital $(100 \mathrm{mg} / \mathrm{kg})$ and were perfused with $4 \%$ paraformaldehyde in phosphate buffered saline (PBS, pH 7.4). Brains were sectioned on a vibratome at $40 \mu \mathrm{m}$ and stored in $1 \times$ $\mathrm{PBS}$ at $4^{\circ} \mathrm{C}$ with sodium azide.

\section{Immunocytochemistry}

For immunocytochemistry, free-floating vibratome sections were treated with $\mathrm{H}_{2} \mathrm{O}_{2}$ to block endogenous peroxidase. Sections were heated to $95^{\circ} \mathrm{C}$ for $5 \mathrm{~min}$ for antigen retrieval. After antigen retrieval, sections were in blocking buffer for $2 \mathrm{~h}$ at room temperature in 10\% normal goat serum, then incubated in the following primary antibodies: (1) rabbit polyclonal antibody for the phosphorylated form of ERK1/2 (Cell Signaling, Catalog \#9101S, lot \#19, 1:100 dilution); (2) rabbit polyclonal antibody to c-fos (Santa Cruz, 1:500 dilution); (3) rabbit polyclonal antibody to Arc/Arg3.1 (generously provided by Paul Worley, Johns Hopkins University, 1:200 dilution). Sections were incubated for $24 \mathrm{~h}$ in the primary antibody and were then washed and incubated in the secondary antibody (goat anti-rabbit IgG, which was used at a dilution of 1:100 in normal goat serum). Subsequent immunocytochemical procedures were as previously described (Wallace et al. 1998). Stained sections were mounted on gelatincoated slides and cover slipped under DPX resin.

The specificity of the primary antibodies used here has been extensively documented. The polyclonal antibody for $\mathrm{p}$-ERK recognizes bands at the expected molecular weights of ERK 1 and 2 in Western blots; antibody binding is seen only when the protein is phosphorylated (manufacturer's product information). The antibody for Arc/Arg3.1 recognizes a single band at the expected molecular weight of $\operatorname{Arc/Arg3.1}$, as documented previously (Lyford et al. 1995). In addition to the evidence for specificity provided by Western blot analyses, the pattern of immunostaining for these antibodies provides strong validation for the specificity of the antibody because staining is strikingly altered by physiological activity (see Results). Double immunostaining with these antibodies was not practical because all are rabbit polyclonal antibodies and thus require the same anti-rabbit secondary antibody.

\section{In situ hybridization}

The cRNA probe for Arc/Arg3.1 has been described previously (Steward et al. 1998). For NRISH, slide-mounted sections or floating vibratome sections were post-fixed with $4 \%$ paraformaldehyde in $0.1 \mathrm{M}$ PBS for $30 \mathrm{~min}$, then rinsed with $0.5 \times$ salinesodium citrate buffer $(0.5 \times$ SSC, $0.1 \%$ diethyl pyrocarbonate [DEPC] treated) for $5 \mathrm{~min}$. Sections were treated with Proteinase $\mathrm{K}(1.25 \mathrm{mg} / \mathrm{L})$ for $30 \mathrm{~min}$, rinsed again with $0.5 \times \mathrm{SSC}(0.1 \% \mathrm{DEPC}$ treated) for $10 \mathrm{~min}$, and air-dried. The sections were covered with $75 \mu \mathrm{L}$ of prehybridization buffer $(2 \times$ SSC, $25 \%$ formamide, $1 \%$ Denhardt's reagent, $10 \%$ dextran sulfate, $0.5 \mathrm{mg} / \mathrm{mL}$ heparin, $0.5 \mathrm{mg} / \mathrm{mL}$ yeast tRNA, and $0.25 \mathrm{mg} / \mathrm{mL}$ of denatured salmon sperm DNA) and incubated at $42^{\circ} \mathrm{C}$ for $2 \mathrm{~h}$. After the prehybridization, about $0.5 \mu \mathrm{g}$ of Dig-cRNA probe in $75 \mu \mathrm{L}$ of hybridization buffer was added to each section. The sections were covered with a baked coverslip and incubated overnight at $55^{\circ} \mathrm{C}$ in a humidified box with $25 \%$ formamide/ $2 \times$ SSC. The next day, the coverslips were removed, and sections were washed with $2 \times \mathrm{SSC} / 10 \mathrm{mM}$ ethylenediaminetetraacetic acid (EDTA) twice (10 min each). The sections were treated with RNAse-A for $30 \mathrm{~min}$ and then washed twice with $2 \times$ SSC/EDTA (10 min per wash). The stringency wash was $0.5 \times \mathrm{SSC} / 10 \mathrm{mM}$ EDTA at $55^{\circ} \mathrm{C}$ for $2 \mathrm{~h}$. Sections were washed with $0.5 \times$ SSC twice ( $10 \mathrm{~min}$ each at room temperature). Alkaline phosphatase conjugated anti-digoxigenin Fab fragment (1:5000) was used to detect the hybridized probes. Nitro-Blue tetrazolium chloride/5-bromo-4-chloro-3'-indolyphosphate p-toluidine salt (NBT/BCIP) solution was applied overnight at $4^{\circ} \mathrm{C}$ to detect the alkaline phosphatase. Sections were washed with $100 \mathrm{mM}$ Tris$\mathrm{HCl}(\mathrm{pH}$ 8.5)/1 mM EDTA three times for 10 min each. Then slides were briefly rinsed with Nanopure water twice and covered with Kaiser's glycerol jelly.

FISH for Arc/Arg3.1 RNA was performed on $20-\mu \mathrm{m}$ coronal sections prepared from flash-frozen brains as described by Guzowski et al. (1999). The Arc/Arg3.1 cRNA riboprobe was generated using the Ambion MaxiScript kit and a premixed RNA labeling nucleotide mix containing digoxigenin-labeled UTP (Roche Molecular Biochemicals). Brain sections were incubated with the digoxigenin-labeled Arc/Arg3.1 antisense riboprobe (1-2 $\mathrm{ng} / \mathrm{mL}$ ) for $16-20 \mathrm{~h}$. After washes of various stringencies, the brain sections were incubated with a horseradish peroxidase (HRP)-conjugated antibody to digoxigenin. The HRP was detected using the Tyramide Signal Amplification fluorescence (TSA-CY3) kit from PerkinElmer. Finally, nuclei were stained with $4^{\prime}$,6diamidino-2-phenylindole (DAPI) stain, and the slides were cover slipped using Vectashield mounting media (Vector Laboratories).

\section{Microscopy and quantitative analysis}

Digital photographs were taken using an Olympus AX80 microscope and Magnafire software. Images were adjusted for contrast and color balance to make them appear comparable to the way they appear in the microscope. For quantitative assessment of immunostaining, optical density (OD) measurements were taken across the granule cell layer and molecular layer of the dentate gyrus using an M4 Microcomputer Imaging Device (MCID). Digital images were collected at $400 \times$ with light intensity adjusted so that areas of maximal labeling were within measuring range, with the lower threshold set at background levels of labeling (i.e., the hilus contralateral to the stimulated side). A series of five OD measurements were taken at $20-\mu \mathrm{m}$ steps, using a $20 \mu \mathrm{m} \times 20 \mu \mathrm{m}$ measuring frame, across the suprapyramidal blade of the dentate gyrus (including the granule cell and molecular layers). The OD values of each experimental group at each step were averaged, and the standard deviation and standard error of the mean were calculated.

For quantitative assessment of FISH, DAPI, and Cy3 images were taken of the dorsal and ventral blades of the dentate gyrus ipsi- and contralateral to the stimulation using the same exposure time. Then, using Image J (NIH), the DAPI images were subjected to a Gaussian blur (radius of 10), the threshold was adjusted to a nonbiased value, and the dentate granule cell layer was outlined using the magic wand tool. The outlines of the granule cell layer were superimposed onto the Cy3 images, and the mean fluorescence intensity over the cell layer was determined. A background measure was taken from a circular region positioned in the hilus where there were no Arc positive neurons, and this background 
value was subtracted from the mean fluorescence over the granule cell body layer.

\section{Statistical analyses}

Data on counts of p-ERK vs. Arc positive neurons (Fig. 6) were analyzed by ANOVA, with post-hoc comparisons at individual time points using paired $t$-tests. Statistical analyses of fluorescence intensity of FISH (Fig. 9) was by un-paired $t$-tests.

\section{Acknowledgments}

This work was supported by NS12333 grant to O.S. We thank Kelli Sharp, Joi Nguyen, and Anastasia Nagel for technical assistance.

\section{References}

Chawla MK, Guzowski JF, Ramirez-Amaya V, Lipa P, Hoffman KL, Marriott LK, Worley PF, McNaughton BL, Barnes CA. 2005. Sparse, environmentally selective expression of Arc RNA in the upper blade of the rodent fascia dentata by brief spatial experience. Hippocampus 10: 579-586.

Coogan AN, O'Leary DM, O'Connor JJ. 1999. P42/44 MAP kinase inhibitor PD98059 attenuates multiple forms of synaptic plasticity in rat dentate gyrus in vitro. J Neurophysiol 81: 103-110.

Davis S, Vanhoutte P, Pages C, Caboche J, Laroche S. 2000. The MAPK/ERK cascade targets both Elk-1 and cAMP response element-binding protein to control long-term potentiation-dependent gene expression in the dentate gyrus in vivo. J Neurosci 20: $4563-4572$.

Dudek SM, Fields RD. 2001. Mitogen-activated protein kinase/extracellular signal-regulated kinase activation in somatodendritic compartments: Roles of action potentials, frequency, and mode of calcium entry. J Neurosci 21: RC122.

Gallagher SM, Daly CA, Bear MF, Huber KM. 2004. Extracellular signalregulated protein kinase activation is required for metabotropic glutamate receptor-dependent long-term depression in hippocampal area CA1. J Neurosci 24: 4859-4864.

Greer PL, Greenberg ME. 2008. From synapse to nucleus: Calciumdependent gene transcription in the control of synapse development and function. Neuron 59: 846-860.

Guzowski JF, McNaughton BL, Barnes CA, Worley PF. 1999. Environmentspecific induction of the immediate early gene Arc in hippocampal neuronal ensembles. Nat Neurosci 2: 1120-1124.

Huang F, Chotiner JK, Steward O. 2007. Actin polymerization and ERK phosphorylation are required for Arc/Arg3.1 mRNA targeting to activated synaptic sites on dendrites. J Neurosci 27: 9054-9067.

Kandel ER. 2001. The molecular biology of memory storage: A dialogue between genes and synapses. Science 294: 1030-1038.

Kawashima T, Okuno H, Nonaka M, Adachi-Morishima A, Kyo N, Okamura M, Takemoto-Kimura S, Worley PF, Bito H. 2009. Synaptic activityresonse element in the Arc/Arg3.1 promoter essential for synapse-tonucleus signaling in activated neurons. Proc Nat Acad Sci 106: 316-321.

Klann E, Dever TE. 2004. Biochemical mechanisms for translational regulation in synaptic plasticity. Nat Rev Neurosci 5: 931-942.

Link W, Konietzko G, Kauselmann G, Krug M, Schwanke B, Frey U, Kuhl K. 1995. Somatodendritic expression of an immediate early gene is regulated by synaptic activity. Proc Natl Acad Sci 92: 5734-5738.

Lyford G, Yamagata K, Kaufmann W, Barnes C, Sanders L, Copeland N, Gilbert D, Jenkins N, Lanahan A, Worley P. 1995. Arc, a growth factor and activity-regulated gene, encodes a novel cytoskeleton-associated protein that is enriched in neuronal dendrites. Neuron 14: 433-445.

Malenka RC, Bear MF. 2004. LTP and LTD: An embarrassment of riches. Neuron 44: 5-21.

Martin KC, Michael D, Rose JC, Barad M, Casadio A, Zhu H, Kandel ER. 1997. MAP kinase translocates into the nucleus of the presynaptic cell and is required for long-term facilitation in Aplysia. Neuron 18: 899912.

Morozov A, Muzzio IA, Bourtchouladze R, Van-Strein N, Lapidus K, Yin D, Winder DG, Adams JP, Sweatt JD, Kandel E. 2003. Rap1 couples cAMP signaling to a distinct pool of p42/44MAPK regulating excitability, synaptic plasticity, learning, and memory. Neuron 39: 309-325.

Panja D, Dagyte G, Bidinosti M, Wibrand K, Kristiansen A-M, Sonenberg N, Bramham CR. 2009. Novel translational control of Arc-dependent long term potentiation consolidation in vivo. J Biol Chem 284: 31498-31511.

Patterson SL, Pittenger C, Morozov A, Martin KC, Scanlin H, Drake C, Kandel E. 2001. Some forms of cAMP-mediated long-lasting potentiation are associated with release of BDNF and nuclear translocation of phospho-MAP kinase. Neuron 32: 123-140.

Pintchovski SA, Peebles CL, Kim HJ, Verdin E, Finkbeiner S. 2009. The serum response factor and a putative novel transcription factor regulate expression of the immediate early gene Arc/Arg3.1 in neurons. J Neurosci 29: 1525-1537.

Schafe GE, Atkins CM, Swank MW, Bauer EP, Sweatt JD, Ledoux J. 2000. Activation of ERK/MAP kinase in the amygdala is required for memory consolidation of Pavlovian fear conditioning. J Neurosci 20: 8177-8187.

Schuman EM, Dynes JL, Steward O. 2006. Synaptic regulation of translation of dendritic mRNAs. J Neurosci 26: 7143-7146.

Selcher JC, Atkins CM, Trzaskos JM, Paylor R, Sweatt JD. 1999. A necessity for MAP kinase activation in mammalian spatial learning. Learn Mem 6: $478-490$.

Steward O, Worley PF. 2001. Selective targeting of newly synthesized Arc mRNA to active synapses requires NMDA receptor activation. Neuron 30: $227-240$.

Steward O, Wallace CS, Lyford GL, Worley PF. 1998. Synaptic activation causes the mRNA for the IEG Arc to localize selectively near activated postsynaptic sites on dendrites. Neuron 21: 741-751.

Steward O, Wallace CS, Worley P. 2001. Synapse-specific gene expression of the IEG Arc: Insights into molecular processes in memory consolidation. In Memory consolidation: Essays in honor of James L. McGaugh (ed. PE Gold, WT Greenough), pp. 35-58. American Psychological Association, Washington, DC.

Steward O, Huang F, Guzowski JF. 2007. A form of perforant path LTP can occur without ERK1/2 phosphorylation or immediate early gene induction. Learn Mem 14: 433-445.

Sweatt JD. 2001. The neuronal MAP kinase cascade: A biochemical signal integration system subserving synaptic plasticity and memory. J Neurochem 76: 1-10.

Temple MD, Steward O. 2003. Visualizing changes in circuit activity resulting from denervation and reinnervation using immediate early gene expression. J Neurosci 23: 2779-2788.

Vazdarjanova A, McNaughton BL, Barnes CA, Worley PF, Guzowski JF. 2002. Experience-dependent coincident expression of the effector immediateearly genes Arc and Homer $1 a$ in hippocampal and neocortical neuronal networks. J Neurosci 22: 10067-10071.

Wallace CS, Lyford GL, Worley PF, Steward O. 1998. Differential intracellular sorting of immediate early gene mRNAs depends on signals in the mRNA sequence. $J$ Neurosci 18: 26-35.

Waltereit R, Dammermann B, Wulff P, Scafidi J, Staubli U, Kauselmann G, Bundman M, Kuhl D. 2001. Arg3.1/Arc mRNA induction by $\mathrm{Ca}^{2+}$ and cAMP requires protein kinase $\mathrm{A}$ and mitogen-activated protein kinase/extracellular regulated kinase activation. J Neurosci 21: 54845493.

Ying SW, Futter M, Rosenblum K, Webber MJ, Hunt SP, Bliss TV, Bramham CR. 2002. Brain-derived neurotrophic factor induces long-term potentiation in intact adult hippocampus: Requirement for ERK activation coupled to CREB and upregulation of Arc synthesis. J Neurosci 22: $1532-1540$.

Received August 27, 2009; accepted in revised form November 30, 2009. 


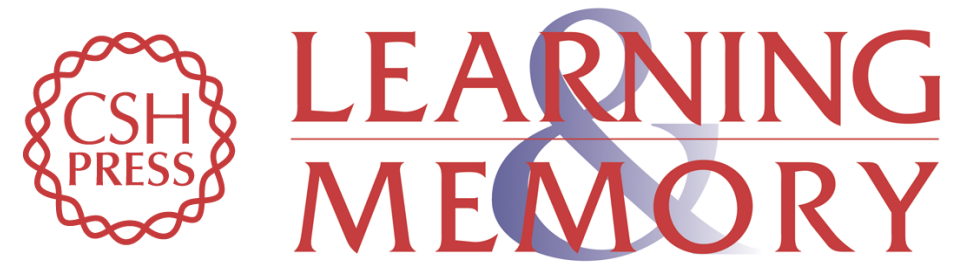

\section{Assessment of the role of MAP kinase in mediating activity-dependent transcriptional activation of the immediate early gene Arc/Arg3.1 in the dentate gyrus in vivo}

Jennifer K. Chotiner, Jessica Nielson, Shannon Farris, et al.

Learn. Mem. 2010, 17:

Access the most recent version at doi: $10.1101 / \mathrm{lm} .1585910$

References This article cites 31 articles, 18 of which can be accessed free at:

http://learnmem.cshlp.org/content/17/2/117.full.html\#ref-list-1

License

Email Alerting Receive free email alerts when new articles cite this article - sign up in the box at the Service top right corner of the article or click here. 